\title{
Retinal Drug Delivery: Rethinking Outcomes for the Efficient Replication of Retinal Behavior
}

\author{
Eliana B. Souto ${ }^{1,2, *(\mathbb{D})}$, Elena Sanchez-Lopez ${ }^{1,3,4} \mathbb{D}^{\mathbb{D}}$, Joana R. Campos ${ }^{1} \mathbb{D}$, Raquel da Ana ${ }^{1}$, \\ Marta Espina ${ }^{3,4}$ D, Maria L. Garcia ${ }^{3,4}$, Patrícia Severino ${ }^{5,6}$, Fernando Batain ${ }^{7}$, \\ Thais F. R. Alves ${ }^{7}{ }^{(D}$, Kessi M. M. Crescencio ${ }^{7}{ }^{(D}$, Selma B. Souto ${ }^{8}$ and Marco V. Chaud ${ }^{7, *(D)}$
}

1 Department of Pharmaceutical Technology, Faculty of Pharmacy, University of Coimbra, Pólo das Ciências da Saúde, Azinhaga de Santa Comba, 3000-548 Coimbra, Portugal; esanchezlopez@ub.edu (E.S.-L.); joanacampos92@gmail.com (J.R.C.); quele.ana@gmail.com (R.d.A.)

2 CEB-Centre of Biological Engineering, University of Minho, Campus de Gualtar, 4710-057 Braga, Portugal

3 Department of Pharmacy, Pharmaceutical Technology and Physical Chemistry, Faculty of Pharmacy Institute of Nanoscience and Nanotechnology (IN2UB), University of Barcelona, 08028 Barcelona, Spain; m.espina@ub.edu (M.E.); marisagarcia@ub.edu (M.L.G.)

4 Centro de Investigación Biomédica en Red de Enfermedades Neurodegenerativas (CIBERNED), University of Barcelona, 08028 Barcelona, Spain

5 University of Tiradentes (Unit) and Institute of Technology and Research (ITP), Nanomedicine and Nanotechnology Laboratory (LNMed) Av. Murilo Dantas, 300, Aracaju 49010-390, Brazil; patricia_severino@itp.org.br

6 Tiradentes Institute, 150 Mt Vernon St, Dorchester, MA 02125, USA

7 Laboratory of Biomaterials and Nanotechnology, University of Sorocaba-UNISO, Sorocaba, São Paulo 18023-000, Brazil; fbatain@gmail.com (F.B.); thaisfrancine1@hotmail.com (T.F.R.A.); kessicrescencio@yahoo.com.br (K.M.M.C.)

8 Department of Endocrinology of Hospital de São João, Alameda Prof. Hernâni Monteiro, 4200-319 Porto, Portugal; u002919@chsj.min-saude.pt

* Correspondence: ebsouto@ff.uc.pt (E.B.S.); marco.chaud@prof.uniso.br (M.V.C.); Tel.: +351-239-488-400 (E.B.S.); +55-15-98153-6692 (M.V.C.)

Received: 17 May 2020; Accepted: 12 June 2020; Published: 21 June 2020

\begin{abstract}
The retina is a highly organized structure that is considered to be "an approachable part of the brain." It is attracting the interest of development scientists, as it provides a model neurovascular system. Over the last few years, we have been witnessing significant development in the knowledge of the mechanisms that induce the shape of the retinal vascular system, as well as knowledge of disease processes that lead to retina degeneration. Knowledge and understanding of how our vision works are crucial to creating a hardware-adaptive computational model that can replicate retinal behavior. The neuronal system is nonlinear and very intricate. It is thus instrumental to have a clear view of the neurophysiological and neuroanatomic processes and to take into account the underlying principles that govern the process of hardware transformation to produce an appropriate model that can be mapped to a physical device. The mechanistic and integrated computational models have enormous potential toward helping to understand disease mechanisms and to explain the associations identified in large model-free data sets. The approach used is modulated and based on different models of drug administration, including the geometry of the eye. This work aimed to review the recently used mathematical models to map a directed retinal network.
\end{abstract}

Keywords: retina; drug delivery; retinal behavior; neuroscience; computational models; mathematical models 


\section{Introduction}

Anatomically, the eye can be compartmentalized into a fibrous tunic layer (sclera, cornea, and conjunctiva), vascular tunic or uvea (choroid, ciliary body, and iris), and an inner coat (retina) [1-3]. The retina, which is made of photoreceptor cells, is a light-sensitive layer of nervous tissue, and is known to be one of the most metabolically active tissues in the human body. The retina is the organ that is responsible for the interpretation and control of our vision, it converts light energy into electrical impulses, which is then transmitted to the brain by the optic nerve $[4,5]$. The outer retina (OR) is the innermost layer of the light-sensitive eye and it is in this structure that the first stage of visual processing occurs [6]. The photoreceptor (PR) cells are anatomical and functional neurons specialized in photon capture and are responsible for the release of electrical responses [7]. The retinal pigment epithelium (RPE), located on the external side of the PR cells, is primarily responsible for supporting the primary visual functions, such as the phagocytosis of the external segments of the PR, retinal recycling (vitamin A), absorption of scattered light, and bidirectional transepithelial transport between the retina and the choriocapillaris, choroid, and the systemic blood circulation [8,9]. These cells have specialized functions in supporting cells and tissue homeostasis, as well as maintaining a healthy retina. Although the retina is a highly specialized and optimized system, organisms do not depend on it for immediate survival, and therefore, it is prone to failure when invaded [10].

For the treatment of eye diseases, the optimal route for drug administration depends on the target tissue, duration of contact, and the disease itself. Diseases of the anterior eye (glaucoma, inflammations, and infections) are treated with eye drops, but due to the complex anatomy and dynamic physiological defense mechanism of the eye, it is known that less than $5 \%$ of the eye drop reaches the posterior chamber of the eye, and negligible penetration is seen through the anterior chamber [11-13]. The eye drops for topical ocular drug delivery have limited success because the drug concentration that hits these tissues is too low. This route has been less explored for treating diseases occurring at the back of the eye [14-17]. For this reason, novel routes and innovative drug delivery systems for intraocular drug delivery injection or transscleral implants have been investigated to reduce the pre-corneal loss. However, it is necessary to consider that both intraocular injections and transscleral implantation are invasive and involve a high risk of side effects.

The parenteral administration via the subconjunctival route delivers the drug underneath the conjunctival membrane, allowing the dose to reach the retina. The first drug delivery route across the transmembrane is via subconjunctival injection. There is thus a growing interest in new ocular drug delivery systems that facilitate the access of the drug to its target, or that can extend its duration of action. However, frequent injections can lead to adverse events, such as intraocular bleeding, infection, and retinal detachment. Transscleral drug delivery has been exploited as an alternative approach over intravitreal injection for drug delivery to the posterior segment of the eye.

For the development of ophthalmic medicines, it is crucial to know how to design the drug release profile, absorption, distribution, metabolism, and excretion kinetics [18]. Drug delivery systems that use polymers or lipids are capable of releasing a drug in a controlled manner based on the physiology and pharmacokinetics of the eye. Since the eye has many membranes, tissues, and fluid flows, it is difficult to quantitatively estimate its effect on drug administration.

Nowadays, intravitreal implants for controlled drug delivery, such as Ozurdez ${ }^{\mathrm{TM}}$ (dexamethasone $0.7 \mathrm{mg}$ ), Iluvien ${ }^{\mathrm{TM}}$ (fluocinolone acetonide $0.19 \mathrm{mg}$ ), and Retisert ${ }^{\mathrm{TM}}$ (fluocinolone $0.59 \mathrm{mg}$ ), as well as intraocular injection, such as Acastin ${ }^{\mathrm{TM}}$ (bevacizumab $1.25 \mathrm{mg}$ ) and Lucentins ${ }^{\mathrm{TM}}$ (ranibizumab $2.3 \mathrm{mg}$ ), are the dosage forms offering improved management of the drug bioavailability and safety profile via the ocular route for the treatment of retinal diseases. However, these drugs are costly and not available for most of the population worldwide. In countries with social inequality, pharmaceutical care is restricted such that quality pharmaceutical care does not reach $90 \%$ of the population. Furthermore, most of the worldwide population will never receive any treatment for intraocular diseases. As such, the traditional model for rethinking new drugs and new strategies of treatment must be overcome. 
New, innovative, and smart scientific strategies need to be put at the forefront of the global science agenda for rethinking outcomes and advance in the knowledge of degenerative retinal diseases.

Due to the complexity and the high level of tissue specialization, the retina is vulnerable to changes that promote its degeneration; therefore, ocular degenerative diseases, such as retinopathies, need to be considered as part of network neuroscience. The linking of empirical and computational developments allows for the opening of new scientific investigations, which include network dynamics, brain network manipulation and control, and the integration of network processes into spatiotemporal domains [19]. Network neuroscience seeks to find new ways to map, record, analyze, and model the elements and interactions of neurobiological systems, taking into account the brain structure and function from an explicitly integrative perspective.

The retinal waves propagate retinal activity that arises from the junction of synaptic intrinsic single-cell properties, excitability, long refractoriness, and network interactions in various vertebrate species, and perform a fundamental role in forming the visual system and retinal circuit $[20,21]$. The recognition of a biophysical approach taking place at the retina is critical for the identification of neuronal elements, transmission capacity for healthy vision, vision in the presence of a disorder, and more recently, for remote development therapies to treat diseases in the posterior and hidden sections of the eyeball.

In brief, the retinal circuitry transforms photoreceptor signals at every synapse [20,22]. Table 1 summarizes the impact of each junction and synaptic transmission on retinal networking. Three successive stages are involved in the formation, development, and maturation of the complex retinal cellular system that makes up the retina. Different classes of synaptic transmissions characterize these three stages, namely, gap junctions, acetylcholine, and glutamate.

Table 1. Impact of the junctions and synaptic transmission on retinal networking.

\begin{tabular}{cccc}
\hline Synaptic Transmission & Main Action & Mediated By & Effect \\
\hline Gap junctions & $\begin{array}{c}\text { Activity-dependent } \\
\text { regulation and plasticity }\end{array}$ & $\begin{array}{c}\text { Electrical synapse coding } \\
\text { ON-OFF directionally } \\
\text { selective ganglion cells }\end{array}$ & $\begin{array}{c}\text { Dynamic interactions } \\
\text { between electrical and } \\
\text { chemical synapses }\end{array}$ \\
\hline Acetylcholine & $\begin{array}{c}\text { To held under a current } \\
\text { clamp }\left(\mathrm{I}_{\mathrm{h}}=0\right) \text { when a } \\
\text { voltage is pulsed from } \\
-70 \mathrm{mV} \text { to } 15 \mathrm{mV} .\end{array}$ & $\begin{array}{c}\text { Transient network } \\
\text { neuron with an } \mathrm{E}_{\mathrm{Cl}}(-70 \\
\mathrm{mV}) \text { manipulation, and } \\
\mathrm{A}_{2} \mathrm{AR} \text { up-regulate SACs' } \\
\text { presynaptic waves. }\end{array}$ & Elicits retinal waves \\
\hline Glutamate & $\begin{array}{c}\text { Ultra-fast response of } \\
\text { photoreceptors synapse }\end{array}$ & P8 and P22 retinas & Restores bursting activity \\
\hline $\begin{array}{l}\mathrm{I}_{\mathrm{h}}: \text { holding cation current, } \mathrm{E}_{\mathrm{Cl}} \text { : membrane potential, } \mathrm{A}_{2} \mathrm{AR} \text { : adenosine } \mathrm{A}(2 \mathrm{~A}) \text { receptor, SACs: starburst amacrine } \\
\text { cells, P8/P22: postnatal days. }\end{array}$ & &
\end{tabular}

Stage I or gap junctions are subjected to activity-dependent regulation and plasticity that controls signal spread through neural networks to keep the postsynaptic membrane close to the membrane potential $\left(\mathrm{E}_{\mathrm{Cl}}\right)[20,22]$. During stage II of retina development, retinal waves are triggered by starburst amacrine cells (SACs), which are transient networking neurons. SACs have a particular asymmetric synaptic distribution of excitatory and inhibitory synapses, and are therefore involved in steering the selectivity in a mature retina. It is a commons sense that SAC activities disappear with maturation. However, Huang et al. described the role of adenosine $\mathrm{A}(2 \mathrm{~A})$ receptor $\left(\mathrm{A}_{2} \mathrm{AR}\right)$ in up-regulating the frequency of retinal waves (stage II) via the presynaptic SAC route. This result provides an important target for the manipulation of retinal waves and new insights into development simulation studies of ocular drug administration based on biophysical approaches [23,24]. In brief, the specific stage II development of waves induced by SACs and mediated by the neurotransmitter acetylcholine is made of a transitory network of autonomous busters that improve the opportunistic local synchrony via 
cholinergic coupling, which can improve wave propagation, depending on the conditions. However, it must be noted that some of these parameters can be pharmacologically controlled [25].

In stage III, the later waves appear to be spatially bound and more localized than stage II waves. These localized activity patterns could potentially have a link to how receptive fields are formed before vision becomes functional $[24,26]$. The light adaptation phenomenon allows the cone response to dominate over rod responses at high illumination. Then, dark-adaptation and light-adaptation processes are related to the rate of regeneration of photopigments and the intracellular concentration of calcium. The photoreceptor synapse, in turn, exhibits a high basal release of glutamate from its axon terminal and affects the activity of the bipolar and horizontal cells. Then, the bipolar cells form a synapse with amacrine and retinal ganglion cells. However, the glutamate-mediated synaptic activity of the retinal bipolar and ganglion cells affects the transmission of visual information via the ganglion cells. Zheng et al. showed that bursting activity in the photoreceptor synapse can be reinitiated pharmacologically in postnatal day P8 (stage III) and postnatal day P22 retinas with chemical agents upon blocking all synaptic connections by applying an antagonist [21,27].

In the developing retina, waves evolve in consecutive stages based on different types of synaptic transmission (gap junctions (stage I), acetylcholine (stage II), and glutamate (stage III)), and are mediated by transient networks of specific cell types [28].

SACs have a special asymmetric synaptic distribution of excitatory and inhibitory synapses, and therefore they are involved in steering the selectivity in the mature retina but they have a different role during early development [29]. Due to autonomous intrinsic cellular mechanisms, these cells exhibit a spontaneous rupture behavior and trigger stage II retinal waves but this activity disappears with maturation [21]. SACs are made of a transitory network of autonomous busters that produce opportunistic local synchrony via cholinergic coupling during stage II, which can form to propagate waves depending on the conditions.

There is a great deal of theoretical information and experimental modeling studies that are available regarding stage II retinal waves but there are still crucial issues that are not addressed in these studies [20]. The models studied so far do not explain the influence of biophysical parameters (conductance) on the activity of SACs during this stage. It is important to consider this point as some of these parameters evolve during development or can be pharmacologically controlled, hence causing effects on SACs [21].

It is known that stage II retinal waves are ubiquitous but some studies have found large variations in the bursting period of SACs across species [30]. Matzakos-Karvouniari et al. proposed that SACs burst because at stage II, they are close to a bifurcation (saddle node) and are triggered by small variations in membrane potential (noise or action of other cells), causing the cell to shift from a resting state to fast oscillations. Following this bifurcation, they remain in the rapid repetitive firing regime, activating the calcium-dependent slow potassium channels and generating a slow hyperpolarization current (SHP) that leads the cell to a homoclinic bifurcation, returning to its resting state and allowing for a long period of hyperpolarization [20]. The authors identified fast voltage-gated potassium channels as the rapid channels responsible for their high activation origin and the fast closure kinetics for rupture, and identified them as Kv3-type $\mathrm{K}^{+}$channel subunits. The voltage-dependent Kv3 channels play an essential role in this recognition process that reduces the neuron's refractory period [30,31]. The presynaptic function of Kv3 channels remains to be investigated. Potassium conductance variation of the Kv3 channels acts on the transient intrinsic properties of SAC excitability during development. Matzakos-Karvouniari et al. proposed that this bifurcation influences the interval between SAC bursts [20]. They observed a wide range of interburst periods between species, which can be explained by the high variability or by an external current. Thus, in cholinergically coupled SACs, the rupture period exhibits intrinsic variability due to simple bifurcation arguments without the need for external mechanisms.

A total of 637 genes responsible for visual impairment or even blindness have been described in the literature and are related to inherited and age-related retinal degenerations. In these 
situations, computational modeling of OR regarding retinal degeneration allows us to understand how these genetic dysfunctions cause process failures, understand their quantitative interdependencies, and discover the pathways that lead to cell death [32].

Regarding vision and eye diseases, there are several in vivo studies available in the literature (including those exploring various imaging modalities and functional assessment), comprehensive genotype-phenotype studies, and histopathological and anatomical studies. Due to the complex interrelationships and limitations of in vitro retinal systems, this theme is not entirely clear and computer modeling thus offers a way to address these challenges $[33,34]$.

The underlying principles of retinal cell biology are very similar to those of other tissues; therefore, this data can be exploited in reusable computational structures. However, it is known that the retina has a special structure involving a laminar organization and high metabolic demands. These constraints reduce the solutions of computer simulations, making this structure attractive to whole-cell and tissue models. Thus, vision-forming retinas have been highly studied by utilizing a set of knowledge and resources in the field of computational biomodeling [33]. Available computational models relate biophysical precision and hardware-adaptable implementation methodologies [35].

Obtaining clinical notes is an expensive process; therefore, the possibility of generating synthetic medical visual data is quite attractive and has been explored. However, for today's computer vision methods, the realistic generation of high-quality medical images is still a challenge [36,37]. The initial methods for medical imaging were based on simplified mathematical models of human anatomy, and over time, they evolved into more complex models that involved the most important aspects of acquisition devices. Thus, the most realistic images are produced by combining anatomical and physiological medical knowledge [38]. These images have many applications, including validating image analysis techniques, medical training, and therapy planning, among others $[36,37,39]$.

The traditional top-down approach is the means used to check available data and draw mathematical models that explain it via image simulation. This approach models complex natural laws through inevitable simplifying assumptions. However, there is a new view in the field of medical imaging, where a bottom-up approach is used to directly derive the most important information from that data. This new approach involves machine learning systems that automatically learn the internal variability of training data [40]. This system, based on the general idea of contradictory learning, is capable of synthesizing natural images, which led to an advance in computer vision. Hardware adaptative optics (HAO) has pushed the limits of optical imaging, which when combined with the optical coherence tomography associated with $\mathrm{HAO}$, has enabled a detailed three-dimensional visualization of photoreceptor distributions and individual nerve fiber bundles in the living human retina [33].

Several models have been created to recreate retinal waves but none can reproduce the autonomous rhythmic disruption of individual SACs and explain the change in intrinsic properties of these cells during development [20]. Based on current vision restoration modes, algorithmic models exhibit a greater correlation between stimuli and the affected neural network; however, the practicality of physical hardware hinders development.

By adapting current processing methods, it is possible to complement large-scale circuit design techniques, which allows for the better physical construction of the artificial retina [35]. To restore vision in patients with degenerative diseases, retinal prosthetic devices have been developed, which through electrical stimulation of the local regions of retinal tissue, bring together spatiotemporal patterns to represent the patient-facing image. These devices have proven to be effective, which has led to the design of various types of devices, many of which are in trials and some are already in the market [41]. For example, Argus II by Second Sight Medical Products Inc. (Sylmar, CA, USA) is already in clinical trials and has been shown to provide patients considerable visual perception to the extent that subjects can recognize objects and differentiate letters. Nevertheless, based on safety limits, $45 \%$ of individual electrodes failed to elicit light perception. Thus, adjacent electrodes are required to locally stimulate 
the cells [42]. These findings allow for a considerable increase in functional vision in blind individuals but new strategies to improve vision have yet to be studied $[43,44]$.

Some tests have already been done to decrease the magnitude of the current required or recreate the desired peak rates in retinal ganglion cells such that the efficiency and effectiveness of the stimulus waveform can be improved [45-47]. Whole-cell simulation is still recent, particularly in mammalian cells, and is therefore considered in biology as one of the challenges of the 21st century.

Whole-cell modeling emerged from developments in proteomics, structural biology, and cryoelectronic microscopy, as well as from trying to understand the dynamic behavior of cells and how the genotype expresses itself in the phenotype. Software development that can simulate whole-cells (E-Cell) or constraint-based genome-scale metabolic network modeling (COBRA toolbox) has been utilized in these fields $[48,49]$. The characteristic anatomy and interaction of the cellular and extracellular compartments means that the manipulation and robust testing using in vitro cell models and OR computational models is crucial [50-52]. Studies of the gene expression profile of RPE and PR cells have shown that most genes expressed in the back of the eye are also expressed in most cells, such that the cell biology is similar to other cell types or tissues and can be placed in a whole-cell model of the OR. There is a huge amount of cellular data available in the literature that can be transposed into computational language, allowing for understanding through membranes (disk membranes in OS), cilia, transporters, and organelles, as well as to verifying the location and movement of proteins, metabolites, and other molecules that perform functions in the external retina. Thus, a reduction in the solution space of computational simulations is expected.

Therefore, understanding and modeling visual system map formation are significant challenges in neurobiology. The approach is modular and is based on different modes of drug administration. There are several different classes of mathematical models of the retina. However, in the first decade of the 21st century, those mathematical models that best respond to the challenges of neurobiology are used to tune single-cell transcription, front-end retinal models for computer vision tasks, and models based on detailed retinal circuits [53]. In this work, we have revised the recently used mathematical models to map the directed retinal network.

\section{Biological Signalling Process of Retina}

The retina is used to study neurosensory processes because it is seen as the organ that gives access to the brain. It is considered a good experimental system because of its anatomical organization (layers of different cell types and extracellular compartments), as well as its easy visualization [6,54]. PR cells detect light that passes through the internal retina and reaches the PRs of the OR. The internal retina has bipolar cells, horizontal cells, Mueller glial cells, and retinal ganglion cells, whose function is to process visual information and to transmit it to the brain. Light is focused onto the photoreceptors that are present on the surface of the retina, then retinal circuits process these signals and convert them into a neural pulse code.

The different photoreceptors contact each other through electrical synapses and contact the bipolar cells through chemical synapses, which in turn communicate with amacrine cells or divert them to ganglion cells for transmission to the occipital lobe of the brain, which finally interprets the neural impulses as a flow of images. In the retina, the information flow traverses a direct path (from photoreceptors to bipolar cells to ganglion cells) and an indirect path (where the AII amacrine cells are interposed between bipolar and ganglion cells). Furthermore, the horizontal and amacrine cells stimulate lateral connectivity among the different pathways [35].

RPE, which is a support cell layer, is next to the PRs. There is a link between the physiology of RPEs and RPs, and therefore vision depends on suitable communication between these two cell types [55]. RPEs are responsible for recycling the visual cycle components, cleaning the PR membrane fragments that were generated in the daily PR renewal, transporting nutrients from the circulation to the subretinal space, and expelling retinal debris [8]. This epithelium belongs to the Bruch basement membrane 
(BBM), which is known to be highly organized and rich in elastin and collagen, which separates the epithelium from fenestrated choroid capillaries [56].

The maturation of RPEs, the BBM, and choroidal blood vessels allows for the creation of the outer blood-retina barrier (oBRB), which is a feature of retinal development. This barrier has as its function the exchange of nutrients, fluids, and residues between the neural retina and the choroid circulation, and is therefore crucial for light transduction in PRs [8,57]. In the formation of the oBRB, the fully mature RPE tight junctions (TJs) are formed, which have the role of limiting the paracellular movement of ions and water through the RPE monolayer and maintain the apical-basal distribution of the RPE transporters [57]. These features are crucial for maintaining retinal homeostasis since they allow for the formation of gradients that lead to directional fluid transport from the neural retina to the choroid [58]. Recent studies have shown that choroid endothelial cells (ECs) act as blood conduits, forming instructive niches for the differentiation, regeneration, and function of parenchymal cells, and may thus intervene in the regulation of ECs [59].

The radial orientation of blood vessels and ganglion cell axons, as well as the planar capillary plexuses, precisely align with the horizontal neural and astrocytic laminae and clearly demonstrate the connection between the vascular and neural structures of the retina. In addition, it is known that the human central retina (fovea) has no vessels. On the other hand, abnormal retinal angiogenesis creates vessels that are not properly oriented and physiologically deformed, and therefore do not adapt to neuronal histology, in turn leading to vision-threatening exudation and bleeding [54].

In humans, the formation or development of vessels in the retina occurs in its most superficial layers and spreads outward from the optic nerve head (center point), reaching the nasal side of the uvea between the retina and the ciliary body before birth [60]. Therefore, from the nascent internal vascular layer, there is the formation of other capillaries in the deeper retinal layers. The choroid is the posterior part of the uvea, which is essentially is a layer of vessels and connective tissue pressed between the retina and sclera. This angiogenic onset is the most common mode of retinal vascular growth but there are other types [61]. Through the concatenation of vascular precursor cells in the form of solid cords that lumenize, new vessels are also formed through vasculogenesis. While studies in this area are lacking, it is thought that this process contributes to superficial plexus growth [62-64].

Michaelson was the forerunner in the use of dye perfusion techniques to reveal embryonic and perinatal retinal vasculature and found that capillaries adjacent to nascent venules grow abundantly and more irregularly around the arteries [65]. Oxygen is known to regulate the growth of blood vessels in the retina and this theory is reinforced by the fact that: (i) Pathological retinal angiogenesis occurs in various diseases marked by retinal ischemia. (ii) Retinal vascularization coincides with developmental processes that indicate local oxygen tension. In late embryogenesis, centrifugal waves of differentiation and proliferation and synaptic connectivity and electrical activity start in the central retina and then diffuse. This pathway is followed by the extension of the superficial vascular plexus, suggesting that metabolic demand and "physiological hypoxia" favor vascular growth. (iii) Oxygen is still responsible for several angiogenic and angioinhibitory factors.

Vascular endothelial growth factor (VEGF) hypoxia-induced cytokine is involved in the formation and development of retinal blood vessels [54]. To create the vascular pattern, VEGF acts in restricted and versatile spatial bands [66]. Retinal capillaries are carefully pruned, which correlates with the reduced production of VEGF messenger RNA (mRNA), as well as endothelial cell apoptosis in these areas.

Hyperoxia next to the arteries is supposed to negatively regulate VEGF production, reducing its actions as a survival factor for endothelial cells $[67,68]$. As the remodulation happens in the retinal perinatal explants, there are other mechanisms of retraction of vessels that are independent of systemically supplied oxygen or immune cells [69].

There are several mechanisms for vascular patterning because VEGF and its receptors are expressed in a non-overlapping manner during retinal vascularization. VEGF is expressed in the developing retina and its receptors (FLK1, FLT1, and neuropilins 1 and 2) are expressed at a different time and in a different spatial form $[70,71]$. Proliferation, migration, orientation, survival, and permeability 
occur due to these receptors, which allows their actions to be delimited by the emergence of receptors through the availability and subtype of ligands. In addition, the same receptor initiates signals that may have different effects on different endothelial cells [72]. Thus, only one growth factor sculpts the developing retinal vasculature through spatiotemporal changes in VEGF and VEGFR distributions.

Differential effects of VEGF isoforms, a distinct spatial range of action, and orientation functions of VEGF isoforms produce alternative transduction of VEGFR activation in different endothelial cells. The relationship between VEGF and other angiogenic or angioinhibitory factors also contributes to the creation of complex vascular networks [73-76].

The study of retinal disorders improves the research and development of new models for retinal angiogenesis, as well as improving the investigation of neurovascular relationships and the development of new antiangiogenic therapies. These studies have determined oxygen to be the main "actor" in retinal angiogenesis, together with metabolic, immune, glial, neuronal, gene expression, and perivascular and progenitor cell factors [54].

Angiogenesis is known to be responsible for tissue growth, development, and repair. Thus, understanding how the various cell types interact to control angiogenesis makes it possible to understand the occurrence of proliferative vascular diseases, such as diabetic retinopathy [77]. Therefore, the retina is seen as a model of the neurovascular system. In recent years, there has been growing interest from scientists, with considerable progress being made in determining the mechanisms that induce and standardize the retinal vascular system, as well as understanding disease processes leading to its disintegration [54].

\section{Computational Modeling of the Retina}

It is necessary to understand how our vision works such that we can create a good hardware-adaptive computational model that properly mimics retinal behavior. An insight into neurophysiological and neuroanatomic processes is required for understanding the nonlinearities and related complexities of neuronal systems. These processes should be considered along with the principles that guide the hardware transformation process to a successful model that can be mapped to a physical device $[78,79]$.

Some simulation studies of the ocular administration of medicines that consider the geometry of the eye are available in the literature. Tojo et al. described models in which the eye was modeled as a cylinder and the partial differential equations were solved using the line method $[80,81]$. In the Wyatt model, anterior chamber drug transport was considered using a self-fabricating finite element algorithm [82].

Balachandran and Barocas [83] and Narasimhan and Vishnampet [84] have considered transscleral drug delivery. In the first study, the calculations were done using the finite element method, and in the second study, the commercial software Fluent was used to apply the finite volume method. Both studies accounted for drug loss via choroid blood flow. Friedrich et al. used the finite element method to model a drug distribution in a rabbit eye after an intravitreal injection [85]. In turn, Haghjou et al. also used Fluent software to model the drug distribution in a rabbit eye after an intravitreal injection [86].

GastroPlus software, which is based on the finite difference method, is being developed for human eye simulations [18]. Kotha et al. developed a virtual pharmacokinetic 3D model of the human eye based on the finite element method (FEM) that is built using Comsol Multiphysics software. This model considers the release of the drug after a polymer adhesive is placed on the sclera [18].

The computational model presented in the research by Eshraghian et al. provides a model that predicts effects on the retina quickly and accurately, gives an extensive understanding of neural responses to visual stimulation, and provides an architecture that can be truly transformed into a hardware device. To obtain the optimal speed and precision, implicit (or semi-implicit) ordinary differential equations ODE were used [35]. The authors present an approach in which they recommend the effective integration of different dynamic time scales into a unified neural response structure, where the stem, cone, amacrine, bipolar, and ganglion cells represent the implemented pathways. 
Using this model, they showed that in comparison to traditional ODE solvers, the adoption of numerical integration accelerates retinal pathway simulations by more than $50 \%$. Thus, they can show a more achievable solution for hardware implementation of retinal predictive models [35].

Wohrer and Kornprobst used a three-layer model with (i) an outer plexiform layer (OPL), (ii) bipolar cells, and (iii) an inner plexiform layer. The OPL accepts data based on experimental recordings that are different from the model of Eshraghian et al. by including recent experimental data, which take into account features that would otherwise not be explained (e.g., bandwidth filtering of electrical signals at the photoreceptor level) [35].

In comparison to the conventional use of ODE solvers, the authors systematically analyzed the two common integral resolution methods to improve the retinal model path simulation performance [87]. To simulate the cellular network in the retina, this model is scalable through lateral connectivity [88]. Transforming a nonlinear system of integral equations uses a numerical technique for the rapid solution of integral equations, achieving the level of computational efficiency required by bio-systems for the evolution and progression of numerical solutions from one step to the next. The model can adapt to the emergence of new data since the parameters and formulations are gathered from the publication of experimental and modeling studies [35].

Venhuizen et al. used a convolutional neural network $(\mathrm{CNN})$ for total retinal segmentation in optical coherence tomography (OCT) to develop an automated system that is resistant to the presence of severe retinal pathology. To explain retinal changes, a generalized U-net network architecture was introduced in this model [89]. The algorithm proposed by the authors was shown to be qualitatively and quantitatively superior compared with the available algorithms because it calculated the macular thickness with an error smaller than the error obtained in the other algorithms. Thus, this study showed that the proposed algorithm can model a wide variability in retinal appearance, with robust and reliable retinal segmentation in any type of pathology.

Real-world irradiation values involve a large range of magnitudes that need to be processed by bionic systems to capture a snapshot of the visual scenes with an exceptional optical sensitivity.

To capture high dynamic range (HDR) images, cameras capable of capturing them are required, where most standard cameras implement the method proposed by Debevec and Malik [90].

Because standard monitors have a low dynamic range (LDR), problems arise in the later viewing of images. Two solutions are proposed: the technical solution, where HDR monitors are used but these are not yet available to the public; and the algorithmic solution, where methods are used to reduce the intensity from HDR to LDR [91]. These methods are known as tone-mapping operators (TMOs) and are designed for still scenes and videos. Over time, there has been intense research on still images according to retinal principles, where the studied approaches combine brightness adjustment and local contrast improvement [92].

There has been a growing interest and development regarding video tone mapping [90]. In neuroscience, it has been shown that comparable TMOs take place at the retina through adjustment mechanisms, which are indispensable once the retina has to preserve contrast sensitivity over this extensive luminance spectrum in ordinary scenes [92].

Benzi et al. developed an innovative TMO based on the strength of an interactive model of the retina [92]. They departed from the Virtual Retina simulator (VRS) that was developed to model the main layers and cell types found in the primate retina. It is grounded in biology and it has been validated using neurophysiological data [93]. This model is considered to be a good example of synergistic model construction since it explores an indispensable interaction between neuroscience and computer vision [53].

It is also interesting for a TMO since it includes a non-trivial contrast gain control (CGC) mechanism, which improves the local contrast in images and even improves coherence in the temporal luminousness. However, VRS still cannot solve the tone-mapping task because it is not designed to handle color or HDR images since there is no photoreception adapter or reading mechanism to produce data regarding 
the multiple retinal responses supplied from different complex cell layers. In this approach, these issues enrich the VRS model, preserve its bio-plausibility, and tests it on standard tone mapping images [92].

Rahman et al. developed a TMO derived from the Retinex algorithm [94]. This yielded a restricted non-linear operator based upon the framework model by Land and McCann, whose study established the interdependence between the eye and brain in color processing, namely, the color constancy effect [95]. The proposed TMO developed by Rahman et al. using the Retinex algorithm processes each color channel independently, which is further unified with the color restoration method [94]. This method has two modes of operation: (1) Single scale, where each color channel is convolved into small Gaussian clusters of different sizes. Each pixel is nonlinearly combined with the surrounding image by defining different pixel interactions at different spatial scales. (2) Multi-scale, where the resulting pixel/surrounding interactions are weighted and summed to obtain the equalized output image. The assignment of the weights is based on a set of rules regarding undersized or oversized surroundings [92].

Reinhard and Devlin developed a TMO motivated by the driveline system adaptation set up in photoreceptors. This model depicts the automatic brightness arrangement that colored photoreceptors have.

The kernel of their algorithms is the evolution of a photoreceptor model and their TMO is based on the overall image adaptation by adjusting the Naka-Rushton computer address in a comprehensive manner (using the average luminousness of the scene) or a specific form (using the average luminousness of the color). This arrangement lacks luminousness coherence over time due to its static formulation, i.e., each piece of the framework is processed individually [92].

Benoit et al. [96,97] and Hérault [98] proposed a front-end retina-like model for computer vision tasks and applied it to tone-mapping images and videos. They modeled the retina in adaptation layers, i.e., the first layer is linked to photoreceptor adaptation and the other is related to ganglion cells. In the middle of these layers, there is a permanent spatial-temporal filter that models the synaptic OPL, which allows for communication between photoreceptors and horizontal retinal cells. The authors present a non-linear specific process where the photoreceptor action mode depends on the luminousness received within a nearby region. The OPL layers were thus employed as spectral lightening and contrast upgrading. In the same way, the ganglion cell layer again uses one non-linear mechanism for photoreceptor adaptation with different parameters. To calculate the average luminosity, the authors considered a small region close to each pixel

Color processing is done using a see-through layer color sampling multiplexing/demultiplexing network (commonly found in cameras). They use the temporal characteristic of the OPL filter to implement a temporal consistency throughout the color sequence [92]. Benoit et al. directly connected the OPL output-to-input ratio with the intended non-linearity in the ganglion cell layer and the virtual retina (VR), where the OPL enters a contrast gain control platform before the ganglion cell layer [96].

Zhang et al. introduced a method for dehazing static images [99]. This method relies on a complete retinal model, i.e., from photoreceptors to retinal ganglion cells. Photoreceptors, bipolar, amacrine, and ganglion cells were modeled as a cascade of Gaussian signals that is a difference of Gaussian filters, which represents the complex associations between colors and the full or specific adaptation.

Matzakos-Karvouniari et al. introduced a mathematical model based on biophysics, where they reproduced the rupture activity of the SACs, proposing a plausible, generic, and robust mechanism for its production [20]. Based on the bifurcation analysis, they provide some biophysical parameters for regulating calcium and potassium activity through burst control.

All models known in the literature describe wave activity, though so far, no models describe the dynamics of individual SACs. In these models, there is no description of the biophysical mechanisms of SAC bursting activity or the role played by biophysical parameters since the models were based on the "simple" description of cellular activity by using a small number of adjustable parameters [20]. The authors based their model on the model proposed by Hennig et al., where the biophysical analysis 
of slow after hyperpolarization (sAHP) dynamics leads to equations and parameter values present in their model $[20,100]$.

Costa et al. proposed a method where they synthesize ocular background images directly from the data [37]. Using the vessel segmentation technique, they combined true images of the fundus with their vessel trees. Thus, the use of these pairs allows for a mapping of a binary vessel tree to a retinal image. For this propose, they used a recent technique of image-to-image translation based on the idea of contradictory learning. The results showed that while the original and generated images shared the same pot tree, they were visually different in overall appearance. Quantitative analysis of the quality of retinal synthetic images has further confirmed that the images produced retained a high proportion of the true quality of the image set [37].

To improve rehabilitation techniques, it is important to include the properties of neural degeneration in these computational approaches [88]. Stimulation thresholds have been well documented in clinical trials involving patients with severe retinal degeneration. It was concluded that the location of the electrode (epi- or subretinal) and the severity of neural degeneration affect the response resulting from electrical stimulation in the pacing range and threshold [101].

In vivo studies have observed increases in stimulation thresholds for indirect, presynaptic activation to retinal ganglion cells but the retina remains responsive if ganglion cells are directly stimulated [102-106].

In a study evaluating the electrophysiological findings of degenerate retinas, it was found that it is possible to alter the spontaneous activity in retinal ganglion cells through pharmacologically inhibiting synapses [107]. In clinical trials, Weitz et al. demonstrated that the use of an enhanced pulse duration stimulates the internal neural circuitry to achieve a higher level of focus on the resulting light response [108].

Computational models represent the death of photoreceptors by considering direct stimulation of ganglion cells or indirect stimulation of ganglion cells through stimulation of presynaptic circuits $[88,109,110]$. Nevertheless, it must be kept in mind that photoreceptor death does not mean the end of the disease since it occurs early and has electrophysiological effects beyond photoreceptors, and light-induced entry into the retinal circuits does not occur. With the progression of the disease, there is a possibility that patients will be completely blind, and therefore there is extensive retinal remodeling, where cell migration and spontaneous neural activity are observed [111,112].

During degeneration remodeling, spontaneous firing and oscillatory behavior were observed in the surviving neural networks. Therefore, removing the entry of light-sensitive cells does not remove neural activity in the retina; in fact, it becomes altered $[113,114]$. The lack of presynaptic entry of degenerate photoreceptors leads to an oscillatory membrane voltage in the cells and thus leads to phasic disruption in the ganglion cells. Some studies have shown that blocking gap junctions can eliminate this activity $[115,116]$.

Previous studies have shown that there are changes in the response to electrical stimulation through these alterations in ganglion cell physiology in degenerating retina and spontaneous activity rates, which can disrupt attempts at systematic electrical stimulation to restore vision [117-119]. Given this information, Loizos et al. proposed a computational model of electrical retinal stimulation to investigate the waveforms used in prosthetic devices to restore lost vision [88]. In this model, there is an association with a connection-based neural network model, which is characterized by precise morphological and synaptic properties, with an admittance method model of bulk tissue and prosthetic electronics. The retina degeneration was modeled by considering cell death and anatomical changes that occur at the onset of the disease, as well as the altered neural behavior that develops throughout neurodegeneration. The authors presented an analysis resulting from the stimulation range and threshold of healthy retinal $\mathrm{ON}$ ganglion cells in the early stages of degeneration, which was compared to the currently used stimulation waveforms, and proposed an asymmetric biphasic current stimulation to subdue the spontaneous firing to allow for increased control over the ganglion cell firing patterns in the degenerate retina [88]. 
The development of a good prosthesis depends on the improvement of predictive models based on the natural signal flow in the retinal network and a better understanding of neural responses to electrical stimulation. Experimental evidence is available in the literature showing that spike timing is needed to explain neural computation, motivating the use of spiking neuron models. This requires detailed biophysical representations of neurons, which use the Hodgkin-Huxley (HH) model [120].

There has been a greater focus on modeling different visual processing pathways in terms of the biophysics of their neuronal activity rather than the construction of image sensors [35]. Recent retinal models simulate neural behaviors, their physiological operations, and reproduce individual neuronal functions or can be combined to replicate a network of neurons. It also considers object-sensitive cells as a function of ganglion cells based on the movement of objects in a scene and the product of self-movement (movements of head and eyes) [121].

Other computational models of retinal ganglion cells include asynchronous or event-controlled algorithms, where faster executions occur because of less wasted time in neuronal behavior calculations without consequent events [35].

Non-instantaneous synaptic interactions exploit the delay structure to speed up simulations, where they present a unique solution for processing spikes in a priority queue in a programmable algorithm [122,123]. However, in hardware translation, buffers and transmission delays are introduced, which in turn removes the advantage it has in theoretical computing. These simulation tools aim to achieve a balance between speed efficiency, memory consumption, and precision in the numerical treatment of the system of equations, as well as create a hardware conversion driven by a very large scale integrated (VLSI) circuit. Several models are expressed using a system of ODEs and continue in differential form without further transformation [124].

All these reasons make mapping into hardware difficult but study into the development of models is still ongoing based on the old mechanistic and integrated computational models to thus provide frameworks to facilitate understanding of disease mechanisms.

\section{Metadata Analysis}

The eye is a very complex organ, for which building a comprehensive model is very challenging. In this section, we have reviewed the recent mathematical models for mapping the retina network.

\subsection{Virtual Pharmacokinetic 3D Model of the Human Eye by Kotha et al. Based on the FEM Using Comsol Multiphysics Software}

This model is based on the retina, focuses on the back of the eye, and contains choroidal blood flow, tissue division, and active transport of the drug at the RPE-choroid limit. It uses the finite element mesh to obtain reliable simulation results, giving no relevance to the step-in time. The concentration of the drug and its average value are given as a function of time in various points of the retina by varying the parameters of the model [18]. Pharmacokinetic modeling is performed with Stella software, where organs are described as dummy boxes and their relationships are defined by reaction or transport equations. The Stella model has previously determined the values of the pharmacokinetic parameters of molecules. However, this model has limitations because it assumes that each organ/computational unit is homogeneous and ignores the distribution of concentrations and the geometry of the sectors under study. Spatial distribution is taken into account when the physical size of an organ is large and chemical processes are controlled by mass transfer. The authors aimed to improve the FEM modeling methodology for initial calculations. For this, it proposes a 3D pharmacokinetic model of the back of the human eye, in which they ignore the cornea, anterior chamber, and lens. In this model, the drug is delivered from a patch placed on the sclera, where the amount that is released that reaches the retina is also calculated as a function of time. Metabolism or protein binding is not included in this model such that it is easier to ensure mass balance at all times, but this inclusion is possible. Thus, this model is built on version $4.3 \mathrm{~b}$ of the Comsol Multiphysics software [18], as well as the previous Femlab, which is most commonly used in biological 
systems, such as heat distribution in the human eye, transdermal drug delivery, and modeling the oxygen distribution in human heart tissues $[125,126]$. Comsol Multiphysics creates simulations for a researcher with basic calculation skills and focuses on creating a model rather than taking into account technical FEM issues or solution algorithms. It considers a polymer implant below the conjunctiva, remaining in the sclera [18]. It is known that in the choroid, the velocity distribution of blood flow has a parabolic profile in the inlets (arteries) that depends on the Poisseulle flow. In this case, the drug is partitioned into the choroid, where some of the drug is flushed out by blood flow in the veins. Thus, for a correct total mass balance to be made, the drug removed from the simulation because of blood circulation must be calculated and integrated as a function of time. To make a quantitative assessment of the drug distribution in the eye, three different points on the retina were selected, i.e., below the drug patch, opposite to the patch, and one point in the "bottom" of the eye. To calculate the average retinal concentration, the total amount of drug in the retina was integrated and divided by the retinal volume. Metabolism is not considered in this model and there is still a lack of information on drug penetration properties in the different membranes of the human eye. However, the authors argue that importing an accurate CT scan image from an eye into Comsol would not alter the simulation results. This model still needs to take into account the modeling of the choroid as a homogeneous domain through which blood flows, as well as modeling the blood veins and pulsation due to cardiac pumping; however, in the Comsol Conference in 2003, blood flow was already considered in artificial flow canals. For a complete treatment of blood veins, a complex model would be required to include all the moving contour elements and conditions in the expanding and contracting vein walls. Therefore, in this simplification, a large error is incurred but the drugs usually have a wide therapeutic window. However, caution should be exercised when using this model for drugs with a narrow therapeutic window [18].

\subsection{Simulation Platform for Neural Computation in the Retina by Eshraghian et al.}

Eshraghian et al. presented a new simulation platform for retinal neural computation based on the transformation of the system of nonlinear ODEs into a set of nonlinear integral equations, which is consistent with the top-down VLSI design methodology [35]. From a mathematical point of view, an ODE system and a system of integral equations are equivalent, where these systems of equations describe identical phenomena. From an algorithmic and circuit perspective, this model has the advantages of higher velocity efficiency of numerical ODE calculations in neural systems without sacrificing accuracy when compared to conventional methods, and features the mapping of neural models derived from biology in VLSI technology and modeling systematic biophysics of the retina at the cellular level. It should be noted that compared to derivatives, integrals are more feasible for mapping in a circuit device since the hardware mapping of integrals only requires sums and derivatives require the use of memory and a delay line to implement them correctly. Implementing good hardware has as challenges the neural algorithms and non-optimal computational behavior of neurons and synapses that apply analog circuits in weak inversion regions [127]. This system mimics the natural flow of signals in the retinal network; therefore, it is better suited for the hardware encoding of retinal networks. In this study, learning is expanded to include amacrine cells and considers the different retinal pathways: (i) rod cell $\rightarrow$ bipolar cell $\rightarrow$ ganglion cell, (ii) cone cell $\rightarrow$ bipolar cell $\rightarrow$ amacrine cell $\rightarrow$ ganglion cell, and (iii) a combination of the two to form a dual pathway (Figure 1) [35]. 


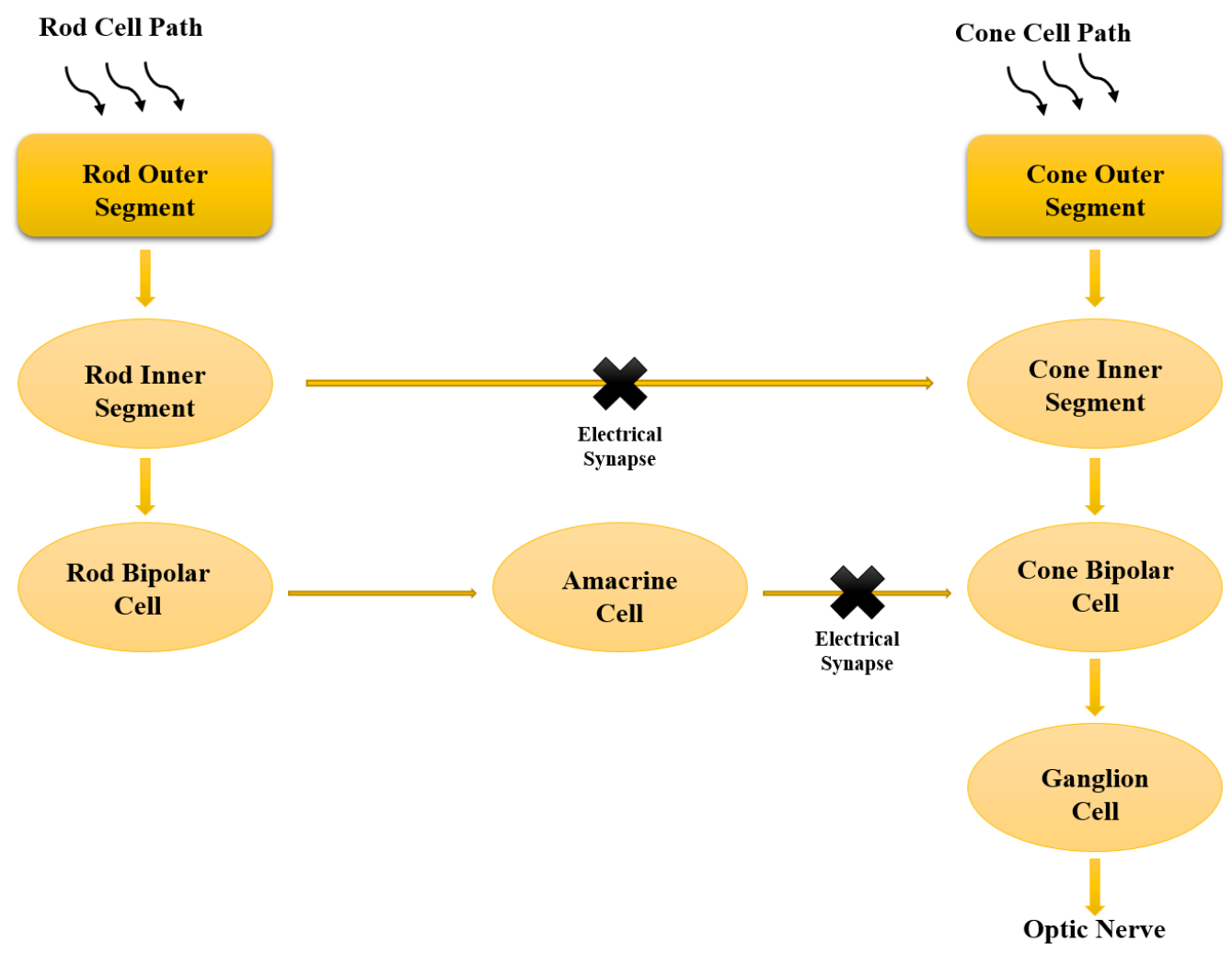

Figure 1. Schematic representation of the bio-flow from photocurrent progression to the ganglion exit. The dual rod and cone pathways are mapping, in which the light signals are transformed into electrical signals that flow from the rod and cone cells through the individual pathways until these signals are integrated into the ganglion cells. Modified after Eshraghian et al. [35].

\subsection{CNN Approach for Retina Segmentation in OCT Volumes}

Venhuizen et al. developed and evaluated a CNN approach for retina segmentation in OCT volumes (Figure 2) [89]. The innovative benefits of this system are its robustness and reliability in the presence of severe retinal pathology, as existing methods have been shown to perform poorly at this level [128]. In cases where the pathology is severe, the correct segmentation of the total retina needs a segmentation algorithm that does not overvalue the retinal structure and shape but takes into account its broad spatial context. Therefore, to meet these requirements, a CNN architecture was proposed in this study. The proposed algorithm performs a semantic segmentation, where each pixel is classified as belonging to the retina or background, rather than directly setting a segmentation boundary. This indirect method of segmenting the retina adds the flexibility needed to properly distinguish retinas as either healthy or pathological. Compared to other pixel classification algorithms, the variability in retinal structure and shape is easily captured by a large number of free parameters present in a typical CNN. To deal with large changes in the retina, it is necessary to include spatially distant information when determining the probability of a retinal pixel. If we consider only a small window around each pixel, the hypo-reflective content of a fluid-filled space can be confused with vitreous fluid or choroidal tissue. Thus, this study introduced the generalized U-net architecture that can include a large spatial context and provides a large receptive field, maintaining location accuracy [89]. The original U-net provides a $140 \times 140$ pixels receptive field. In this network, segmentation errors occur for certain pixels with large abnormalities since they do not have sufficient contextual information to differentiate them from the vitreous fluid or choroidal tissue $[89,129]$. Briefly, the authors note that for the original network, with a receptive field of $140 \times 140$ pixels, segmentation errors occur within the fluid-filled abnormality because the lower/upper retina is not included in the receptive field, which gives the network the impression that the pixel is part of the choroid tissue or the vitreous fluid. 
They found that when increasing the receptive field to $572 \times 572$ pixels, this error did not occur because all abnormalities in the receptive field were included and enough contextual information was included to make a correct classification. The algorithm proposed in this study was compared to two reference algorithms, one provided by an OCT camera manufacturer and the other widely used in research environments, which is based on the segmentation of individual retinal layers to delimit the retina and obtain related measurements. Therefore, a large deviation in this layered structure (e.g., a fluid-filled space) results in errors in the segmentation outputs obtained by these algorithms [89].

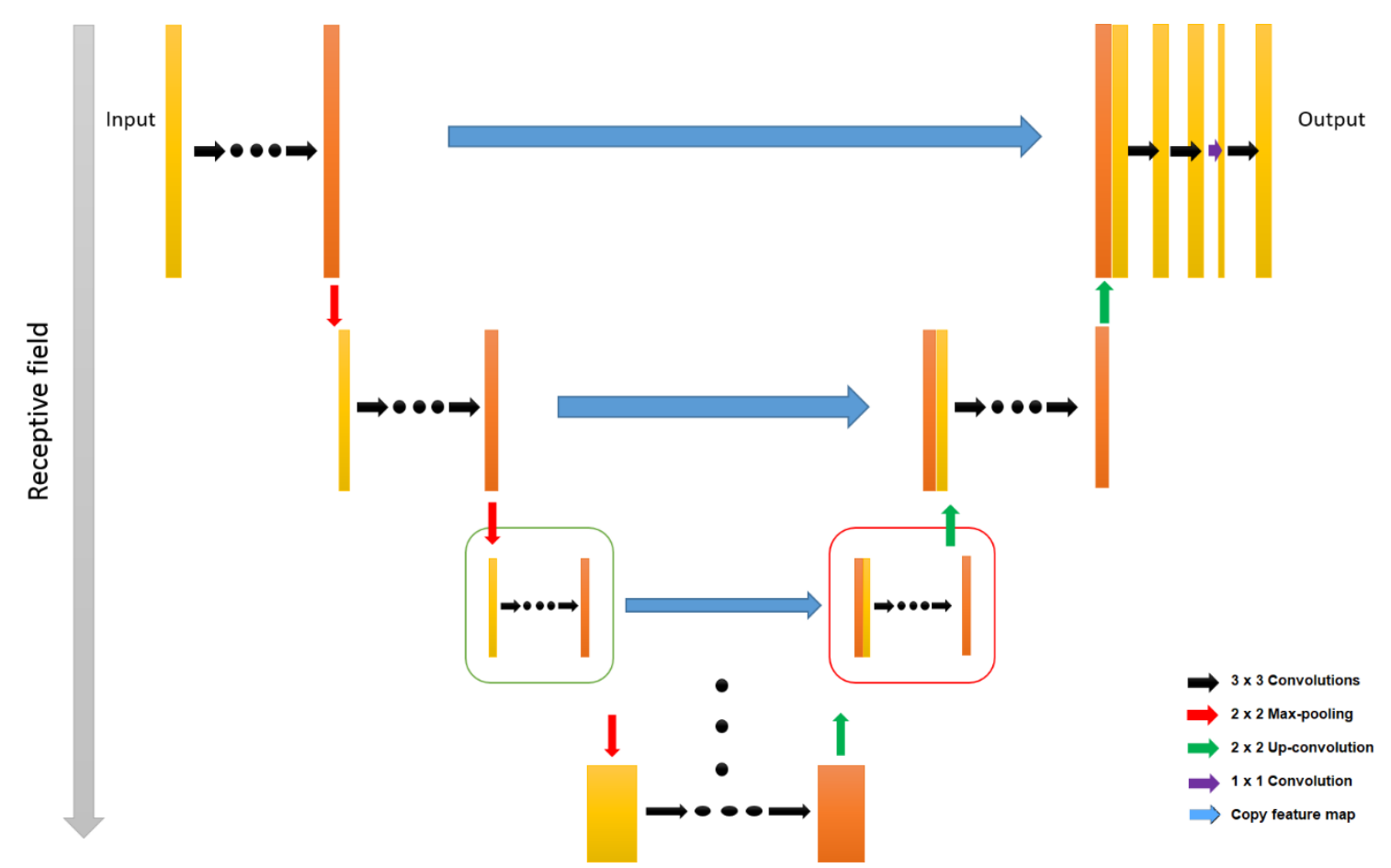

Figure 2. Schematic representation of a U-net architecture. Left-hand side box indicates the basic down-sample and right-hand side box indicates the up-sampled units. Modified after Venhuizen et al. [89].

\subsection{Tone Method Operators Supported by a Synergistic Model of the Retina}

Benzi et al. provided a complete TMO supported by a synergistic retinal system from the Virtual Retina simulator that was designed to model the key layers and kind of cells found in the primate retina (Figure 3) [92]. The Virtual Retina has been developed to be an implementable retinal model that enables large scale and complex mathematical operations with proper data processing in an appropriate biological time. The proposed model involves an inseparable spatiotemporal linear filtering of the external plexiform layer, bipolar cell-level deviation feedback, and a peak generation process through noisy leakage integration and neuron electricity pulses to produce RGC patterns. This TMO has the following stages: (1) Pre-processing stages, where there is a change to HDR-RGB input color image to luminousness area and the calibration of the lightness data such that these values are mapped to the full luminousness of the real scenery. (2) An elaborate retinal process, where there is complete photoreceptor adaption that considers the incorporated contractile aperture in the center of the iris of the eye (pupil), which adapts to the input level of the following the VR design. (3) The image editing process, where the definition of the reading provides for significant amounts of retina data of the VR and is accompanied by colorization and gamma correction to achieve an LDR-RGB image, which allows for the adaption of frame-by-frame photoreceptors and luminousness consistency using temporal filtering on the contrast gain control layers. This approach has advantages in comparison to general video tone mapping because this process does not require a prior optical flux evaluation. 
In these methods, the optical flow has been used to steady small movements in a scene, with the limitation of producing artefacts in scenes with more sweeping motions. In addition, this model takes into account the specific contrast information in space that best maintains spatial details [92].

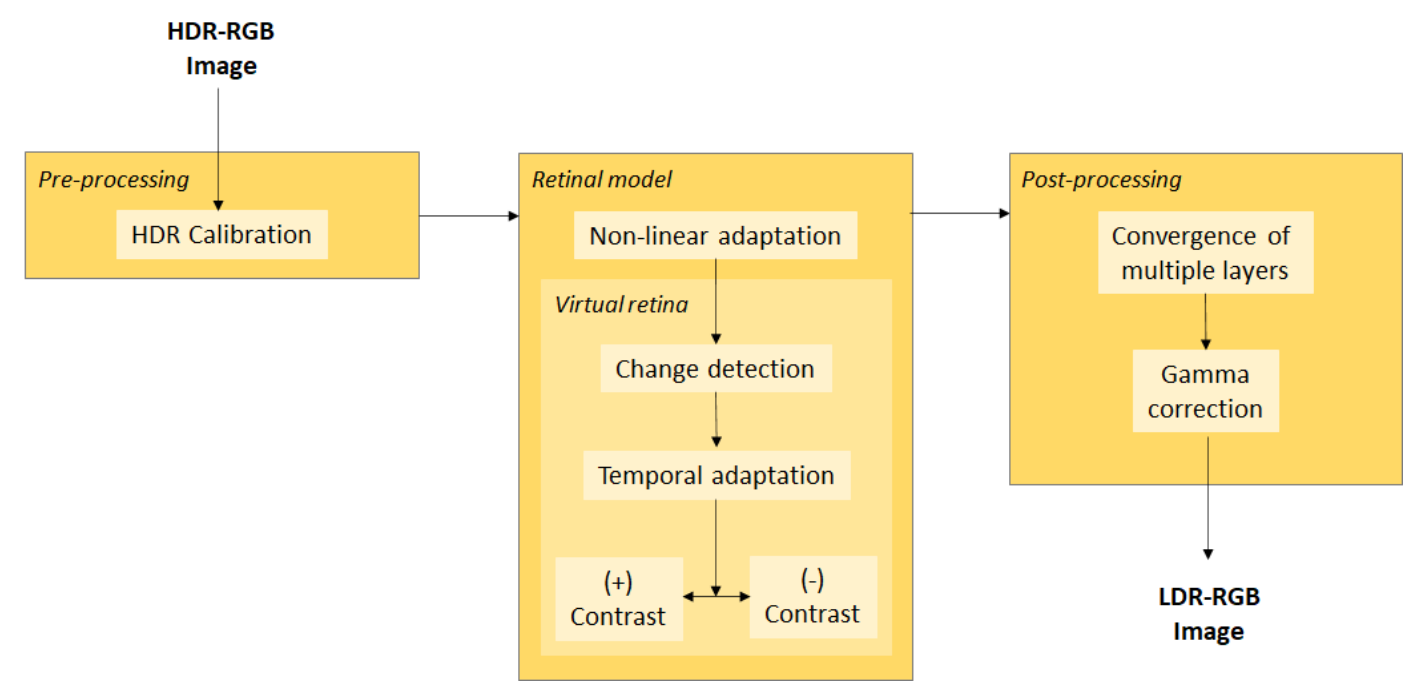

Figure 3. Schematic description of the pre-processing, retina model using Virtual Retina, and post-processing general operator. HDR: high dynamic range, RGB: Red, Green, Blue color model, OPL: outer plexiform layer, CGC: contrast gain control, LDR: low dynamic range. Modified after Benzi et al. [92].

\subsection{Adversarial Retinal Image Synthesis}

Costa et al. proposed a method that synthesizes the eye bottom's images directly from the data. In this model, a random noise generator synthesizes the images and an auxiliary discriminator system trained in real data identifies the reality of the generated data [37]. During the training process, the generator learns to produce images that present a classification problem that increases the difficulty for the discriminator. Although adverse techniques are very successful in natural imaging, their application to medical imaging is still incipient due to the lack of significant amounts of training data and the difficulty of properly controlling the output of the opposing generator. In the work by Costa and his collaborators, they applied the adversarial learning framework to retinal images. Instead of generating images from scratch, the authors generated plausible new images from binary retinal vessel trees [37]. Thus, the task of the generator remains achievable, where it is only necessary to learn to generate part of the retinal content (e.g., optical disk or background texture). The visual and quantitative results demonstrated in the paper prove the feasibility of learning how to synthesize new retinal images from a data set of retinal vessel tree pairs and the corresponding retinal images by applying current-generating contradictory models. Moreover, the size of the images produced $(512 \times 512)$ was even larger than the images commonly generated in general computer vision problems.

\subsection{Computational Model of Electrical Stimulation of the Retina}

Loizos et al. proposed a computer model of electrical retinal stimulation to investigate waveforms already used in prosthetic devices to restore partial vision lost by retinal degenerative diseases [41]. To understand the degenerate retinal response to electrical stimulation used and to develop new electrode geometries and stimulus waveforms, the authors provided a simulation framework for increasing the effectiveness of electrical stimulation. Based on previous work, the framework was developed as a multi-scale and multiphysics simulation platform where the Admittance Method is used to compute the electric field within a tissue model and NEURON is used to simulate the resulting response in a neural network [130]. The Admittance Method is assumed to be a quasi-static 
electromagnetic field solver, where a voxelized model that is discretized by tissue/material dielectric properties is constructed first. It takes as data the input between each node in the model and a set of current sources, where a set of linear equations is constructed and an iterative solver is used to calculate the voltage at each node in the model [131]. Based on a connectivity dataset, a model of a ganglion cell network with a realistic cell morphology and synaptic type, distribution, and weight is built on NEURON [132]. In the study by Loizos et al. [41], the biophysical data available in the literature were incorporated into each cell and a script was also written to apply the extracellular electric field from Admittance Method simulations to observe the resulting network and cellular behavior at a given input. The intrinsic properties of AII amacrine cells within this model were altered (following Choi et al.) to produce an oscillatory membrane potential and induce spontaneous neural activity that mimics a degenerated retina [116]. For this study, translating a connectome dataset into a computational model is a uniquely qualified approach since it is composed of a real image morphology and observed connections that allow for greater precision in the representation of a retinal neural network and the resulting network behavior, which reduces the need for assumptions about interconnectivity. Thus, it allows for the representation of cell death within the internal plexiform layer by "degenerating" the computational retina and decreasing the strength of individual synapses or gap junctions and the number of cells. A bulk tissue and prosthetic electronics model were constructed on a larger spatial scale using the Admittance Method to calculate the extracellular electric field due to anatomical changes in the early stages of degeneration. Connecting the extracellular space model of the Admittance Method model to the connectome-based NEURON model combines the ability to alter the anatomical structure of the retina, integrate implant electronics, and alter the biophysical properties of cells and interconnectivity to virtually degenerate the retina.

The detailed study from Loizos et al. [41], of degenerated retinal electrical stimulation includes knowledge gained through electrophysiological studies of cellular behavior, the comprehensive maps of connections, geometric and electrical characteristics of prosthetic electrode arrays, and clinical and experimental data on degeneration, as well as computational electromagnetism, all in one simulation platform (Figure 4). In this study, the stimulation threshold and interval were calculated for varying degrees of degeneration and complexity of the neural network, and a stimulation waveform that reduces spontaneous activity within a degenerate retina is created, which provides more effective control over ganglion cell stimulation. The results showed that retinal ganglion cell stimulation thresholds do not vary much after the early stages of retinal degeneration. The simulation of the proposed asymmetric waveforms also showed the ability to improve the control of the ganglion cell firing via electrical stimulation [41].

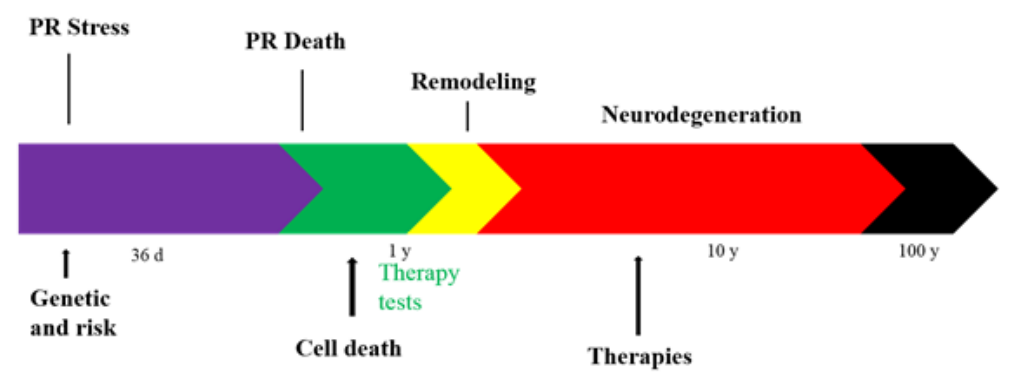

Figure 4. Diagram of the timeline of retina degeneration. PR: Photoreceptor.

\section{Conclusions}

The data sets relevant to the retina, eye, and vision offer numerous opportunities but it is still difficult to understand and develop new interventions that improve human visual health. There is a large amount of development of mechanistic and integrated computational models that provide frameworks to facilitate the understanding of disease mechanisms and to explain patterns identified in model-free data sets. Exploring current research on retinal processing may be considered a promising 
approach to addressing the challenges of computer photography. Kotha et al. created a 3D Comsol Multiphysics model of the human eye that simulates the spatiotemporal distribution of a drug in the eye that is delivered from an adhesive placed on the sclera. This model studies the effect of drug concentration on the retina through transport and equilibrium parameters. The accuracy of the simulations was validated by calculating the total mass balance, ensuring no artificial accumulation or disappearance of the drug. Thus, by using Comsol modeling, one can easily study the effect of various model parameters on the distribution of a drug. In the model, the computational efficiency, the ease of implementation in VLSI technology, and the simplicity of a systematic biophysical model were shown. For this set of simulations, better performance was demonstrated using an integration approach compared with a more sophisticated implicit ODE method. Numerical errors evolve within neural systems and between the two pathways in the presence and absence of electrical synapses as gap junctions. They also provide an assessment of how timescales within dynamic systems influence the signal flow transformation and numerical errors through nonlinear neural systems. In this model, only one computational block is the complete retinal architecture, which must be mapped directly to all components of the cell. The authors presented a hardware-adaptive computational retina model that involved promoting the intermediate step that allows humans to retrieve meaningful sensory information based on limited information. This provides future insight into the development of 3D chip architecture. The CNN that has been shown to model variability in retinal appearance resulted in robust retinal segmentation. This method also supports reliable clinical measurements based on retinal segmentation (CMT measurements). The use of this model in clinical studies, where manual correction of segmentation limits is undesirable, requires a segmentation algorithm that produces reliable clinical measurements. Thus, in clinical retinal practice, an automated system performing in this range is considered a reliable alternative to time-consuming subjective measurements of retinal thickness. As the CGC layer is the one that ensures temporal coherence, the use of TMO video inspired by the retina properties, which provides local luminance information as a supervisory signal in the video, could improve the performance of recognition tasks. However, this TMO had limitations regarding videos that consisted of the current coloring method and generated color flickers in the output. This was justified by the fact that the original model of the virtual retina is monochrome. Therefore, this model contains factors linked to the different stages of full and specific adaptation of the data luminousness image. However, for a detailed analysis, the complementary contributions of each stage of computing, i.e., bringing together the best aspects of TMOs into a single TMO, is still under study. Costa et al. proposed a method that synthesizes ocular background images directly from the data by using an image-to-image translation technique that is based on contradictory learning and achieved good resolution. In this method, retinal images show a repetitive geometry, where high-level structures (field of view, optical disc, or macula) are present in the image and act as a guide for the model to learn how to produce new textures and background intensities. However, this method relies on a pre-existing vessel tree to generate a new image. Furthermore, if the vessel tree comes from applying a segmentation technique to the original image, the potential weaknesses of the segmentation algorithm will be inherited by the synthesized image. Finally, Loizos et al. proposed a multiscale multiphysics computational framework to model the electrical stimulation of the degenerate retina. Through this structure, they investigated the effects of the cellular network connectivity, anatomical changes, and spontaneous activity observed in the degenerate retina during attempts at electrical stimulation. They proposed a more effective waveform on the degenerate retina that applies asymmetric biphasic pulses to reduce spontaneous neural activity and allow for greater control over time of the action potentials of the ganglion cells. With the development of the integrative computational tools, their limitations will be alleviated. Regarding the human retina, data on cell types are still incomplete and there is controversy regarding the connectivity of different cells. It is also necessary to understand the functioning of systemic phenomena and their interaction with local retinal processes, as well as the long period in which vision diseases develop, making the relevance of many acute experimental data (in vivo and in vitro) uncertain. Thus, it is necessary to improve the monitoring of disease progression 
and capture aging in quantitative ways to improve model construction. Successful prospects are foreseen due to the current diversity of data generated, the increasing sophistication of modeling approaches, and the increased available computing power. The knowledge presented in this review may result in the future development of better and more efficient visual prostheses that enables better brain imaging for visually impaired people.

Author Contributions: E.S.-L., R.D.A., and J.R.C. wrote and formatted the review. E.B.S., M.E., M.L.G., P.S., S.B.S., and M.V.C. reviewed and edited the article. E.S.-L., R.D.A., J.R.C., F.B., T.F.R.A., K.M.M.C., and S.B.S. contributed to the writing and preparation of figures. E.B.S., M.E., M.L.G., and M.V.C. conceptualized, structured, reviewed, and supervised the literature research. All authors made a substantial contribution to this review. All authors have read and agreed to the published version of the manuscript.

Funding: The authors acknowledge the financial support received from the Portuguese Science and Technology Foundation (FCT/MCT) and the European Funds (PRODER/COMPETE) for the project UIDB/04469/2020 (strategic fund), co-financed by FEDER, under the Partnership Agreement PT2020. The authors also acknowledge FAPESP São Paulo Research Foundation, for the financial support for the publication of the article.

Conflicts of Interest: The authors declare no conflict of interest.

\section{Abbreviations}

$\begin{array}{ll}\text { BBM } & \text { Bruch basement membrane } \\ \text { CGC } & \text { Contrast gain control } \\ \text { CNN } & \text { Convolutional neural network } \\ \text { ECs } & \text { Choroid endothelial cells } \\ \text { FEM } & \text { Finite element method } \\ \text { HAO } & \text { Hardware adaptative optics } \\ \text { HDR } & \text { High dynamic range } \\ \text { HH } & \text { Hodgkin-Huxley } \\ \text { LDR } & \text { Low dynamic range } \\ \text { mRNA } & \text { Messenger RNA } \\ \text { oBRB } & \text { Outer blood-retina barrier } \\ \text { OCT } & \text { Optical coherence tomography } \\ \text { ODEs } & \text { Ordinary differential equations } \\ \text { OPL } & \text { Outer plexiform layer } \\ \text { OR } & \text { Outer retina } \\ \text { OS } & \text { Outer segments } \\ \text { PR } & \text { Photoreceptor } \\ \text { RPE } & \text { Retinal pigment epithelium } \\ \text { SACs } & \text { Starburst amacrine cells } \\ \text { SHP } & \text { Slow hyperpolarization current } \\ \text { TJs } & \text { Tight junctions } \\ \text { TMOs } & \text { Tone mapping operators } \\ \text { VEGF } & \text { Vascular endothelial growth factor } \\ \text { VLSI } & \text { Very large scale integrated } \\ \text { VR } & \text { Virtual Retina }\end{array}$

\section{References}

1. Fangueiro, J.F.; Veiga, F.; Silva, A.M.; Souto, E.B. Ocular Drug Delivery-New Strategies for Targeting Anterior and Posterior Segments of the Eye. Curr. Pharm. Des. 2016, 22, 1135-1146. [CrossRef] [PubMed]

2. Sanchez-Lopez, E.; Egea, M.A.; Davis, B.M.; Guo, L.; Espina, M.; Silva, A.M.; Calpena, A.C.; Souto, E.M.B.; Ravindran, N.; Ettcheto, M.; et al. Memantine-Loaded PEGylated Biodegradable Nanoparticles for the Treatment of Glaucoma. Small 2018, 14, 1701808. [CrossRef]

3. Souto, E.B.; Dias-Ferreira, J.; Lopez-Machado, A.; Ettcheto, M.; Cano, A.; Camins Espuny, A.; Espina, M.; Garcia, M.L.; Sanchez-Lopez, E. Advanced Formulation Approaches for Ocular Drug Delivery: State-Of-The-Art and Recent Patents. Pharmaceutics 2019, 11, 460. [CrossRef] [PubMed] 
4. Querques, L.; Parravano, M.; Borrelli, E.; Chiaravalloti, A.; Tedeschi, M.; Sacconi, R.; Zucchiatti, I.; Bandello, F.; Querques, G. Anatomical and functional changes in neovascular AMD in remission: Comparison of fibrocellular and fibrovascular phenotypes. Br. J. Ophthalmol. 2020, 104, 47-52. [CrossRef]

5. Cho, H.J.; Kim, K.; Lim, S.H.; Kang, D.H.; Kim, J.W. Retinal pigment epithelial atrophy after anti-vascular endothelial growth factor therapy for polypoidal choroidal vasculopathy. Br. J. Ophthalmol. 2020, 10, 1136. [CrossRef] [PubMed]

6. Hoon, M.; Okawa, H.; Della Santina, L.; Wong, R.O.L. Functional architecture of the retina: Development and disease. Prog. Retin. Eye Res. 2014, 42, 44-84. [CrossRef] [PubMed]

7. Palczewski, K. Chemistry and biology of the initial steps in vision: The Friedenwald lecture. Investig. Ophthalmol. Vis. Sci. 2014, 55, 6651-6672. [CrossRef] [PubMed]

8. Strauss, O. The Retinal Pigment Epithelium in Visual Function. Physiol. Rev. 2005, 85, 845-881. [CrossRef]

9. Kevany, B.M.; Palczewski, K. Phagocytosis of retinal rod and cone photoreceptors. Physiology 2010, 25, 8-15. [CrossRef] [PubMed]

10. Cartwright, R.A.; Schwartz, R.S.; Merry, A.L.; Howell, M.M. The importance of selection in the evolution of blindness in cavefish. BMC Evol. Biol. 2017, 17, 45. [CrossRef]

11. Sanchez-Lopez, E.; Egea, M.A.; Cano, A.; Espina, M.; Calpena, A.C.; Ettcheto, M.; Camins, A.; Souto, E.B.; Silva, A.M.; Garcia, M.L. PEGylated PLGA nanospheres optimized by design of experiments for ocular administration of dexibuprofen-in vitro, ex vivo and in vivo characterization. Colloids Surf. B Biointerfaces 2016, 145, 241-250. [CrossRef] [PubMed]

12. Fangueiro, J.F.; Calpena, A.C.; Clares, B.; Andreani, T.; Egea, M.A.; Veiga, F.J.; Garcia, M.L.; Silva, A.M.; Souto, E.B. Biopharmaceutical evaluation of epigallocatechin gallate-loaded cationic lipid nanoparticles (EGCG-LNs): In vivo, in vitro and ex vivo studies. Int J. Pharm. 2016, 502, 161-169. [CrossRef] [PubMed]

13. Abrego, G.; Alvarado, H.; Souto, E.B.; Guevara, B.; Bellowa, L.H.; Parra, A.; Calpena, A.; Garcia, M.L. Biopharmaceutical profile of pranoprofen-loaded PLGA nanoparticles containing hydrogels for ocular administration. Eur. J. Pharm. Biopharm. 2015, 95, 261-270. [CrossRef] [PubMed]

14. Gonzalez-Mira, E.; Nikolic, S.; Calpena, A.C.; Egea, M.A.; Souto, E.B.; Garcia, M.L. Improved and safe transcorneal delivery of flurbiprofen by NLC and NLC-based hydrogels. J. Pharm. Sci. 2012, 101, 707-725. [CrossRef] [PubMed]

15. Araujo, J.; Garcia, M.L.; Mallandrich, M.; Souto, E.B.; Calpena, A.C. Release profile and transscleral permeation of triamcinolone acetonide loaded nanostructured lipid carriers (TA-NLC): In vitro and ex vivo studies. Nanomedicine 2012, 8, 1034-1041. [CrossRef]

16. Gonzalez-Mira, E.; Egea, M.A.; Souto, E.B.; Calpena, A.C.; Garcia, M.L. Optimizing flurbiprofen-loaded NLC by central composite factorial design for ocular delivery. Nanotechnology 2010, 22, 045101. [CrossRef]

17. Araujo, J.; Nikolic, S.; Egea, M.A.; Souto, E.B.; Garcia, M.L. Nanostructured lipid carriers for triamcinolone acetonide delivery to the posterior segment of the eye. Colloids Surf. B Biointerfaces 2011, 88, 150-157. [CrossRef]

18. Kotha, S.; Murtomäki, L. Virtual pharmacokinetic model of human eye. Math. Biosci. 2014, 253, 11-18. [CrossRef]

19. Bassett, D.S.; Sporns, O. Network neuroscience. Nat. Neurosci. 2017, 20, 353-364. [CrossRef]

20. Matzakos-Karvouniari, D.; Gil, L.; Orendorff, E.; Marre, O.; Picaud, S.; Cessac, B. A biophysical model explains the spontaneous bursting behavior in the developing retina. Sci. Rep. 2019, 9, 1859. [CrossRef]

21. Zheng, J.; Lee, S.; Zhou, Z.J. A transient network of intrinsically bursting starburst cells underlies the generation of retinal waves. Nat. Neurosci. 2006, 9, 363-371. [CrossRef] [PubMed]

22. Joselevitch, C. Human retinal circuitry and physiology. Psychol. Neurosci. 2008, 1, 141-165. [CrossRef]

23. Huang, P.-C.; Hsiao, Y.-T.; Kao, S.-Y.; Chen, C.-F.; Chen, Y.-C.; Chiang, C.-W.; Lee, C.-F.; Lu, J.-C.; Chern, Y.; Wang, C.-T. Adenosine A2A Receptor Up-Regulates Retinal Wave Frequency via Starburst Amacrine Cells in the Developing Rat Retina. PLoS ONE 2014, 9, e95090. [CrossRef] [PubMed]

24. Chiang, C.W.; Chen, Y.C.; Lu, J.C.; Hsiao, Y.T.; Chang, C.W.; Huang, P.C.; Chang, Y.T.; Chang, P.Y.; Wang, C.T. Synaptotagmin I regulates patterned spontaneous activity in the developing rat retina via calcium binding to the C2AB domains. PLoS ONE 2012, 7, e47465. [CrossRef] [PubMed]

25. Hanson, L.; Sethuramanujam, S.; deRosenroll, G.; Jain, V.; Awatramani, G.B. Retinal direction selectivity in the absence of asymmetric starburst amacrine cell responses. eLife 2019, 8. [CrossRef] [PubMed] 
26. Maccione, A.; Hennig, M.H.; Gandolfo, M.; Muthmann, O.; van Coppenhagen, J.; Eglen, S.J.; Berdondini, L.; Sernagor, E. Following the ontogeny of retinal waves: Pan-retinal recordings of population dynamics in the neonatal mouse. J. Physiol. 2014, 592, 1545-1563. [CrossRef]

27. Sun, Y.; Smith, L.E.H. Retinal Vasculature in Development and Diseases. Annu. Rev. Vis. Sci. 2018, 4, 101-122. [CrossRef]

28. Kerschensteiner, D. Glutamatergic Retinal Waves. Front. Neural Circuits 2016, 10, 38. [CrossRef]

29. Fried, S.I.; Münch, T.A.; Werblin, F.S. Mechanisms and circuitry underlying directional selectivity in the retina. Nature 2002, 420, 411-414. [CrossRef]

30. Agrahari, V.; Mandal, A.; Agrahari, V.; Trinh, H.M.; Joseph, M.; Ray, A.; Hadji, H.; Mitra, R.; Pal, D.; Mitra, A.K. A comprehensive insight on ocular pharmacokinetics. Drug Deliv. Transl. Res. 2016, 6, 735-754. [CrossRef]

31. Labro, A.J.; Priest, M.F.; Lacroix, J.J.; Snyders, D.J.; Bezanilla, F. Kv3.1 uses a timely resurgent K+ current to secure action potential repolarization. Nat. Commun. 2015, 6, 10173. [CrossRef] [PubMed]

32. Wright, A.F.; Chakarova, C.F.; Abd El-Aziz, M.M.; Bhattacharya, S.S. Photoreceptor degeneration: Genetic and mechanistic dissection of a complex trait. Nat. Rev. Genet. 2010, 11, 273-284. [CrossRef] [PubMed]

33. Shemonski, N.D.; South, F.A.; Liu, Y.-Z.; Adie, S.G.; Scott Carney, P.; Boppart, S.A. Computational high-resolution optical imaging of the living human retina. Nat. Photonics 2015, 9, 440-443. [CrossRef] [PubMed]

34. Semple, J.L.; Woolridge, N.; Lumsden, C.J. Review: In Vitro, in Vivo, in Silico: Computational Systems in Tissue Engineering and Regenerative Medicine. Tissue Eng. 2005, 11, 341-356. [CrossRef] [PubMed]

35. Eshraghian, J.K.; Baek, S.; Kim, J.-H.; Iannella, N.; Cho, K.; Goo, Y.S.; Iu, H.H.C.; Kang, S.-M.; Eshraghian, K. Formulation and Implementation of Nonlinear Integral Equations to Model Neural Dynamics Within the Vertebrate Retina. Int. J. Neural Syst. 2018, 28, 1850004. [CrossRef] [PubMed]

36. Zhao, H.; Li, H.; Maurer-Stroh, S.; Cheng, L. Synthesizing retinal and neuronal images with generative adversarial nets. Med. Image Anal. 2018, 49, 14-26. [CrossRef] [PubMed]

37. Costa, P.; Galdran, A.; Meyer, M.I.; Niemeijer, M.; Abràmoff, M.; Mendonça, A.M.; Campilho, A. End-to-End Adversarial Retinal Image Synthesis. IEEE Trans. Med. Imaging 2018, 37, 781-791. [CrossRef] [PubMed]

38. Collins, D.L.; Zijdenbos, A.P.; Kollokian, V.; Sled, J.G.; Kabani, N.J.; Holmes, C.J.; Evans, A.C. Design and construction of a realistic digital brain phantom. IEEE Trans. Med. Imaging 1998, 17, 463-468. [CrossRef] [PubMed]

39. Hodneland, E.; Hanson, E.; Munthe-Kaas, A.Z.; Lundervold, A.; Nordbotten, J.M. Physical Models for Simulation and Reconstruction of Human Tissue Deformation Fields in Dynamic MRI. IEEE Trans. Biomed. Eng. 2016, 63, 2200-2210. [CrossRef]

40. van Tulder, G.; de Bruijne, M. Why Does Synthesized Data Improve Multi-sequence Classification. In Medical Image Computing and Computer-Assisted Intervention-MICCAI 2015, Proceedings of the International Conference on Medical Image Computing and Computer-Assisted Intervention, Munich, Germany, 5-9 October 2015; Springer: Cham, Switzerland, 2015; pp. 531-538.

41. Loizos, K.; Marc, R.; Humayun, M.; Anderson, J.R.; Jones, B.W.; Lazzi, G. Increasing Electrical Stimulation Efficacy in Degenerated Retina: Stimulus Waveform Design in a Multiscale Computational Model. IEEE Trans. Neural Syst. Rehabil. Eng. 2018, 26, 1111-1120. [CrossRef]

42. Weiland, J.D.; Humayun, M.S. Retinal Prosthesis. IEEE Trans. Biomed. Eng. 2014, 61, 1412-1424. [CrossRef] [PubMed]

43. Ahuja, A.K.; Yeoh, J.; Dorn, J.D.; Caspi, A.; Wuyyuru, V.; McMahon, M.J.; Humayun, M.S.; Greenberg, R.J.; Dacruz, L. Factors Affecting Perceptual Threshold in Argus II Retinal Prosthesis Subjects. Transl. Vis. Sci. Technol. 2013, 2, 1. [CrossRef] [PubMed]

44. Ho, A.C.; Humayun, M.S.; Dorn, J.D.; da Cruz, L.; Dagnelie, G.; Handa, J.; Barale, P.-O.; Sahel, J.-A.; Stanga, P.E.; Hafezi, F.; et al. Long-Term Results from an Epiretinal Prosthesis to Restore Sight to the Blind. Ophthalmology 2015, 122, 1547-1554. [CrossRef] [PubMed]

45. Weitz, A.C.; Behrend, M.R.; Ahuja, A.K.; Christopher, P.; Wei, J.; Wuyyuru, V.; Patel, U.; Greenberg, R.J.; Humayun, M.S.; Chow, R.H.; et al. Interphase gap as a means to reduce electrical stimulation thresholds for epiretinal prostheses. J. Neural Eng. 2014, 11, 016007. [CrossRef]

46. Hadjinicolaou, A.E.; Savage, C.O.; Apollo, N.V.; Garrett, D.J.; Cloherty, S.L.; Ibbotson, M.R.; Brien, B.J.O. Optimizing the Electrical Stimulation of Retinal Ganglion Cells. IEEE Trans. Neural Syst. Rehabil. Eng. 2015, 23, 169-178. [CrossRef] 
47. Fried, S.I.; Hsueh, H.A.; Werblin, F.S. A Method for Generating Precise Temporal Patterns of Retinal Spiking Using Prosthetic Stimulation. J. Neurophysiol. 2006, 95, 970-978. [CrossRef]

48. Tomita, M.; Hashimoto, K.; Takahashi, K.; Shimizu, T.S.; Matsuzaki, Y.; Miyoshi, F.; Saito, K.; Tanida, S.; Yugi, K.; Venter, J.C.; et al. E-CELL: Software environment for whole-cell simulation. Bioinformatics 1999, 15, 72-84. [CrossRef]

49. Becker, S.A.; Feist, A.M.; Mo, M.L.; Hannum, G.; Palsson, B.Ø.; Herrgard, M.J. Quantitative prediction of cellular metabolism with constraint-based models: The COBRA Toolbox. Nat. Protoc. 2007, 2, 727-738. [CrossRef]

50. Song, Z.; Postma, M.; Billings, S.A.; Coca, D.; Hardie, R.C.; Juusola, M. Stochastic, adaptive sampling of information by microvilli in fly photoreceptors. Curr. Biol. 2012, 22, 1371-1380. [CrossRef]

51. Song, Z.; Juusola, M. Refractory sampling links efficiency and costs of sensory encoding to stimulus statistics. J. Neurosci. 2014, 34, 7216-7237. [CrossRef]

52. Juusola, M.; Dau, A.; Song, Z.; Solanki, N.; Rien, D.; Jaciuch, D.; Dongre, S.A.; Blanchard, F.; de Polavieja, G.G.; Hardie, R.C.; et al. Microsaccadic sampling of moving image information provides Drosophila hyperacute vision. eLife 2017, 6, e26117. [CrossRef] [PubMed]

53. Medathati, N.V.K.; Neumann, H.; Masson, G.S.; Kornprobst, P. Bio-inspired computer vision: Towards a synergistic approach of artificial and biological vision. Comput. Vis. Image Underst. 2016, 150, 1-30. [CrossRef]

54. Gariano, R.F.; Gardner, T.W. Retinal angiogenesis in development and disease. Nature 2005, 438, 960-966. [CrossRef] [PubMed]

55. Benedicto, I.; Lehmann, G.L.; Ginsberg, M.; Nolan, D.J.; Bareja, R.; Elemento, O.; Salfati, Z.; Alam, N.M.; Prusky, G.T.; Llanos, P.; et al. Concerted regulation of retinal pigment epithelium basement membrane and barrier function by angiocrine factors. Nat. Commun. 2017, 8, 15374. [CrossRef]

56. Booij, J.C.; Baas, D.C.; Beisekeeva, J.; Gorgels, T.G.M.F.; Bergen, A.A.B. The dynamic nature of Bruch's membrane. Prog. Retin. Eye Res. 2010, 29, 1-18. [CrossRef]

57. Rizzolo, L.J. Development and role of tight junctions in the retinal pigment epithelium. Int. Rev. Cytol. 2007, 258, 195-234.

58. Caceres, P.S.; Benedicto, I.; Lehmann, G.L.; Rodriguez-Boulan, E.J. Directional Fluid Transport across Organ-Blood Barriers: Physiology and Cell Biology. Cold Spring Harb. Perspect. Biol. 2017, 9, a027847. [CrossRef]

59. Rafii, S.; Butler, J.M.; Ding, B.-S. Angiocrine functions of organ-specific endothelial cells. Nature 2016, 529, 316-325. [CrossRef]

60. Connolly, S.E.; Hores, T.A.; Smith, L.E.H.; D'Amore, P.A. Characterization of vascular development in the mouse retina. Microvasc. Res. 1988, 36, 275-290. [CrossRef]

61. Qazi, Y.; Maddula, S.; Ambati, B.K. Mediators of ocular angiogenesis. J Genet 2009, 88, 495-515. [CrossRef]

62. Gariano, R.F. Cellular mechanisms in retinal vascular development. Prog. Retin. Eye Res. 2003, 22, $295-306$. [CrossRef]

63. Flower, R.W.; McLeod, D.S.; Lutty, G.A.; Goldberg, B.; Wajer, S.D. Postnatal retinal vascular development of the puppy. Investig. Ophthalmol. Vis. Sci. 1985, 26, 957-968.

64. Chan-Ling, T.; Halasz, P.; Stone, J. Development of retinal vasculature in the cat: Processes and mechanisms. Curr. Eye Res. 1990, 9, 459-478. [CrossRef]

65. Michaelson, I.C. The mode of development of the vascular system of the retina, with some observations on its significance for certain retinal diseases. Trans. Ophthalmol. Soc. UK 1948, 68, 137-180.

66. Stalmans, I.; Ng, Y.-S.; Rohan, R.; Fruttiger, M.; Bouché, A.; Yuce, A.; Fujisawa, H.; Hermans, B.; Shani, M.; Jansen, S.; et al. Arteriolar and venular patterning in retinas of mice selectively expressing VEGF isoforms. J. Clin. Investig. 2002, 109, 327-336. [CrossRef] [PubMed]

67. Claxton, S.; Fruttiger, M. Role of arteries in oxygen induced vaso-obliteration. Exp. Eye Res. 2003, 77, 305-311. [CrossRef]

68. Alon, T.; Hemo, I.; Itin, A.; Pe'er, J.; Stone, J.; Keshet, E. Vascular endothelial growth factor acts as a survival factor for newly formed retinal vessels and has implications for retinopathy of prematurity. Nat. Med. 1995, 1, 1024-1028. [CrossRef] [PubMed]

69. Curatola, A.M.; Moscatelli, D.; Norris, A.; Hendricks-Munoz, K. Retinal blood vessels develop in response to local VEGF-A signals in the absence of blood flow. Exp. Eye Res. 2005, 81, 147-158. [CrossRef] 
70. Shih, S.-C.; Ju, M.; Liu, N.; Smith, L.E.H. Selective stimulation of VEGFR-1 prevents oxygen-induced retinal vascular degeneration in retinopathy of prematurity. J. Clin. Investig. 2003, 112, 50-57. [CrossRef] [PubMed]

71. Gariano, R.F.; Hu, D.; Helms, J. Expression of angiogenesis-related genes during retinal development. Gene Expr. Patterns 2006, 6, 187-192. [CrossRef] [PubMed]

72. Gerhardt, H.; Golding, M.; Fruttiger, M.; Ruhrberg, C.; Lundkvist, A.; Abramsson, A.; Jeltsch, M.; Mitchell, C.; Alitalo, K.; Shima, D.; et al. VEGF guides angiogenic sprouting utilizing endothelial tip cell filopodia. J. Cell Biol. 2003, 161, 1163-1177. [CrossRef] [PubMed]

73. Carmeliet, P.; Tessier-Lavigne, M. Common mechanisms of nerve and blood vessel wiring. Nature 2005, 436, 193-200. [CrossRef] [PubMed]

74. Feeney, S.A.; Simpson, D.A.C.; Gardiner, T.A.; Boyle, C.; Jamison, P.; Stitt, A.W. Role of Vascular Endothelial Growth Factor and Placental Growth Factors During Retinal Vascular Development and Hyaloid Regression. Investig. Ophthalmol. Vis. Sci. 2003, 44, 839-847. [CrossRef] [PubMed]

75. Sarlos, S.; Rizkalla, B.; Moravski, C.J.; Cao, Z.; Cooper, M.E.; Wilkinson-Berka, J.L. Retinal angiogenesis is mediated by an interaction between the angiotensin type 2 receptor, VEGF, and angiopoietin. Am. J. Pathol. 2003, 163, 879-887. [CrossRef]

76. Dawson, D.W.; Volpert, O.V.; Gillis, P.; Crawford, S.E.; Xu, H.-J.; Benedict, W.; Bouck, N.P. Pigment Epithelium-Derived Factor: A Potent Inhibitor of Angiogenesis. Science 1999, 285, 245-248. [CrossRef] [PubMed]

77. Walpole, J.; Mac Gabhann, F.; Peirce, S.M.; Chappell, J.C. Agent-based computational model of retinal angiogenesis simulates microvascular network morphology as a function of pericyte coverage. Microcirculation 2017, 24, e12393. [CrossRef] [PubMed]

78. Eshraghian, J.K.; Baek, S.; Cho, K.; Iannella, N.; Kim, J.; Goo, Y.S.; Iu, H.H.C.; Fernando, T.; Eshraghian, K. Modelling and analysis of signal flow platform implementation into retinal cell pathway. In Proceedings of the 2016 IEEE Asia Pacific Conference on Circuits and Systems (APCCAS), Jeju, Korea, 25-28 October 2016; pp. 491-494.

79. Draghici, S. Neural networks in analog hardware-Design and implementation issues. Int. J. Neural Syst. 2000, 10, 19-42. [CrossRef]

80. Tojo, K. A Pharmacokinetic Model for Ocular Drug Delivery. Chem. Pharm. Bull. 2004, 52, 1290-1294. [CrossRef]

81. Tojo, K.J.; Ohtori, A. Pharmacokinetic model of intravitreal drug injection. Math. Biosci. 1994, 123, 59-75. [CrossRef]

82. Wyatt, H.J. Modelling Transport in the Anterior Segment of the Eye. Optom. Vis. Sci. 2004, 81, $272-282$. [CrossRef]

83. Balachandran, R.K.; Barocas, V.H. Computer Modeling of Drug Delivery to the Posterior Eye: Effect of Active Transport and Loss to Choroidal Blood Flow. Pharm. Res. 2008, 25, 2685-2696. [CrossRef] [PubMed]

84. Narasimhan, A.; Vishnampet, R. Effect of choroidal blood flow on transscleral retinal drug delivery using a porous medium model. Int. J. Heat Mass Transf. 2012, 55, 5665-5672. [CrossRef]

85. Friedrich, S.; Cheng, Y.-L.; Saville, B. Finite element modeling of drug distribution in the vitreous humor of the rabbit eye. Ann. Biomed. Eng. 1997, 25, 303-314. [CrossRef] [PubMed]

86. Haghjou, N.; Abdekhodaie, M.J.; Cheng, Y.L.; Saadatmand, M. Computer modeling of drug distribution after intravitreal administration. World Acad. Sci. Eng. Technol. 2011, 77, 706-716.

87. Cho, K.; Baek, S.; Cho, S.W.; Kim, J.H.; Goo, Y.S.; Eshraghian, J.K.; Iannella, N.; Eshraghian, K. Signal Flow Platform for Mapping and Simulation of Vertebrate Retina for Sensor Systems. IEEE Sens. J. 2016, 16, 5856-5866. [CrossRef]

88. Loizos, K.; Lazzi, G.; Lauritzen, J.S.; Anderson, J.; Jones, B.W.; Marc, R. A multi-scale computational model for the study of retinal prosthetic stimulation. In Proceedings of the 2014 36th Annual International Conference of the IEEE Engineering in Medicine and Biology Society, Chicago, IL, USA, 26-30 August 2014.

89. Venhuizen, F.G.; van Ginneken, B.; Liefers, B.; van Grinsven, M.J.J.P.; Fauser, S.; Hoyng, C.; Theelen, T.; Sánchez, C.I. Robust total retina thickness segmentation in optical coherence tomography images using convolutional neural networks. Biomed. Opt. Express 2017, 8, 3292-3316. [CrossRef]

90. Debevec, P.; Malik, J. Recovering High Dynamic Range Radiance Maps from Photographs. In Proceedings of the 24th International Conference on Computer Graphics and Interactive Techniques, Los Angeles, CA, USA, 3-8 August 1997; pp. 369-378. [CrossRef] 
91. Reinhard, E.; Devlin, K. Dynamic range reduction inspired by photoreceptor physiology. IEEE Trans. Vis. Comput. Graph. 2005, 11, 13-24. [CrossRef]

92. Benzi, M.; Escobar, M.J.; Kornprobst, P. A bio-inspired synergistic virtual retina model for tone mapping. Comput. Vis. Image Underst. 2018, 168, 21-36. [CrossRef]

93. Wohrer, A.; Kornprobst, P. Virtual Retina: A biological retina model and simulator, with contrast gain control. J. Comput. Neurosci. 2009, 26, 219-249. [CrossRef]

94. Rahman, Z.U.; Jobson, D.; Woodell, G. Multiscale retinex for color rendition and dynamic range compression. In Applications of Digital Image Processing XIX; SPIE: Bellingham, WA, USA, 1996; Volume 2847.

95. Land, E.H.; McCann, J.J. Lightness and Retinex Theory. J. Opt. Soc. Am. 1971, 61, 1-11. [CrossRef]

96. Benoit, A.; Alleysson, D.; Herault, J.; Le Callet, P. Spatio-temporal tone mapping operator based on a retina model. In International Workshop on Computational Color Imaging; Springer: Berlin, Germany, 2009.

97. Benoit, A.; Caplier, A.; Durette, B.; Herault, J. Using Human Visual System modeling for bio-inspired low level image processing. Comput. Vis. Image Underst. 2010, 114, 758-773. [CrossRef]

98. Herault, J. Color Processing in the Retina. In Vision: Images, Signals and Neural Networks; Progress in Neural Processing: Volume 19; World Scientific: Singapore; London, UK; Hackensack, NJ, USA, 2010; pp. 141-172.

99. Zhang, X.-S.; Gao, S.-B.; Li, C.-Y.; Li, Y.-J. A Retina Inspired Model for Enhancing Visibility of Hazy Images. Front. Comput. Neurosci. 2015, 9, 151. [CrossRef] [PubMed]

100. Hennig, M.H.; Adams, C.; Willshaw, D.; Sernagor, E. Early-stage waves in the retinal network emerge close to a critical state transition between local and global functional connectivity. J. Neurosci. 2009, 29, 1077-1086. [CrossRef] [PubMed]

101. O’Hearn, T.M.; Sadda, S.R.; Weiland, J.D.; Maia, M.; Margalit, E.; Humayun, M.S. Electrical stimulation in normal and retinal degeneration (rd1) isolated mouse retina. Vis. Res. 2006, 46, 3198-3204. [CrossRef] [PubMed]

102. Suzuki, S.; Humayun, M.S.; Weiland, J.D.; Chen, S.-J.; Margalit, E.; Piyathaisere, D.V.; de Juan, E. Comparison of Electrical Stimulation Thresholds in Normal and Retinal Degenerated Mouse Retina. Jpn. J. Ophthalmol. 2004, 48, 345-349. [CrossRef] [PubMed]

103. Jensen, R.J. Activation of ganglion cells in wild-type and $\mathrm{P} 23 \mathrm{H}$ rat retinas with a small subretinal electrode. Exp. Eye Res. 2012, 99, 71-77. [CrossRef] [PubMed]

104. Jensen, R.J.; Rizzo, J.F. Activation of ganglion cells in wild-type andrd1mouse retinas with monophasic and biphasic current pulses. J. Neural Eng. 2009, 6, 35004. [CrossRef]

105. Jensen, R.J.; Rizzo, J.F. Activation of retinal ganglion cells in wild-type and rd1 mice through electrical stimulation of the retinal neural network. Vis. Res. 2008, 48, 1562-1568. [CrossRef]

106. Sekirnjak, C.; Hulse, C.; Jepson, L.H.; Hottowy, P.; Sher, A.; Dabrowski, W.; Litke, A.M.; Chichilnisky, E.J. Loss of responses to visual but not electrical stimulation in ganglion cells of rats with severe photoreceptor degeneration. J. Neurophysiol. 2009, 102, 3260-3269. [CrossRef]

107. Sekirnjak, C.; Jepson, L.H.; Hottowy, P.; Sher, A.; Dabrowski, W.; Litke, A.M.; Chichilnisky, E.J. Changes in physiological properties of rat ganglion cells during retinal degeneration. J. Neurophysiol. 2011, 105, 2560-2571. [CrossRef]

108. Weitz, A.C.; Nanduri, D.; Behrend, M.R.; Gonzalez-Calle, A.; Greenberg, R.J.; Humayun, M.S.; Chow, R.H.; Weiland, J.D. Improving the spatial resolution of epiretinal implants by increasing stimulus pulse duration. Sci. Transl. Med. 2015, 7, 318ra203. [CrossRef] [PubMed]

109. Jepson, L.H.; Hottowy, P.; Mathieson, K.; Gunning, D.E.; Dabrowski, W.; Litke, A.M.; Chichilnisky, E.J. Focal electrical stimulation of major ganglion cell types in the primate retina for the design of visual prostheses. J. Neurosci. 2013, 33, 7194-7205. [CrossRef] [PubMed]

110. Abramian, M.; Lovell, N.H.; Morley, J.W.; Suaning, G.J.; Dokos, S. Activation and inhibition of retinal ganglion cells in response to epiretinal electrical stimulation: A computational modelling study. J. Neural Eng. 2014, 12, 16002. [CrossRef] [PubMed]

111. Jones, B.W.; Watt, C.B.; Frederick, J.M.; Baehr, W.; Chen, C.-K.; Levine, E.M.; Milam, A.H.; Lavail, M.M.; Marc, R.E. Retinal remodeling triggered by photoreceptor degenerations. J. Comp. Neurol. 2003, 464, 1-16. [CrossRef] [PubMed]

112. Jones, B.W.; Pfeiffer, R.L.; Ferrell, W.D.; Watt, C.B.; Tucker, J.; Marc, R.E. Retinal Remodeling and Metabolic Alterations in Human AMD. Front. Cell. Neurosci. 2016, 10, 103. [CrossRef] [PubMed] 
113. Trenholm, S.; Awatramani, G.B. Origins of spontaneous activity in the degenerating retina. Front. Cell. Neurosci. 2015, 9, 277. [CrossRef] [PubMed]

114. Borowska, J.; Trenholm, S.; Awatramani, G.B. An Intrinsic Neural Oscillator in the Degenerating Mouse Retina. J. Neurosci. 2011, 31, 5000-5012. [CrossRef]

115. Toychiev, A.H.; Ivanova, E.; Yee, C.W.; Sagdullaev, B.T. Block of gap junctions eliminates aberrant activity and restores light responses during retinal degeneration. J. Neurosci. 2013, 33, 13972-13977. [CrossRef]

116. Choi, H.; Zhang, L.; Cembrowski, M.S.; Sabottke, C.F.; Markowitz, A.L.; Butts, D.A.; Kath, W.L.; Singer, J.H.; Riecke, H. Intrinsic bursting of AII amacrine cells underlies oscillations in the rd1 mouse retina. J. Neurophysiol. 2014, 112, 1491-1504. [CrossRef]

117. Cho, A.; Ratliff, C.; Sampath, A.; Weiland, J. Changes in ganglion cell physiology during retinal degeneration influence excitability by prosthetic electrodes. J. Neural Eng. 2016, 13, 025001. [CrossRef]

118. Goo, Y.S.; Park, D.J.; Ahn, J.R.; Senok, S. Spontaneous oscillatory rhythms in the degenerating mouse retina modulate retinal ganglion cell responses to electrical stimulation. Front. Cell. Neurosci. 2016, 9. [CrossRef] [PubMed]

119. Park, D.J.; Senok, S.S.; Goo, Y.S. Degeneration stage-specific response pattern of retinal ganglion cell spikes in rd10 mouse retina. In Proceedings of the 2015 37th Annual International Conference of the IEEE Engineering in Medicine and Biology Society (EMBC), Milan, Italy, 25-29 August 2015; pp. 3351-3354.

120. Hodgkin, A.L.; Huxley, A.F. A quantitative description of membrane current and its application to conduction and excitation in nerve. J. Physiol. 1952, 117, 500-544. [CrossRef] [PubMed]

121. Martínez-Cañada, P.; Morillas, C.; Pino, B.; Ros, E.; Pelayo, F. A Computational Framework for Realistic Retina Modeling. Int. J. Neural Syst. 2016, 26, 1650030. [CrossRef] [PubMed]

122. Lee, G.; Farhat, N.H. The double queue method: A numerical method for integrate-and-fire neuron networks. Neural Netw. 2001, 14, 921-932. [CrossRef]

123. Momiji, H.; Bharath, A.A.; Hankins, M.W.; Kennard, C. Numerical study of short-term afterimages and associate properties in foveal vision. Vis. Res. 2006, 46, 365-381. [CrossRef]

124. Momiji, H.; Hankins, M.W.; Bharath, A.A.; Kennard, C. A numerical study of red-green colour opponent properties in the primate retina. Eur. J. Neurosci. 2007, 25, 1155-1165. [CrossRef]

125. Radisic, M.; Deen, W.; Langer, R.; Vunjak-Novakovic, G. Mathematical model of oxygen distribution in engineered cardiac tissue with parallel channel array perfused with culture medium containing oxygen carriers. Am. J. Physiol. Circ. Physiol. 2005, 288, H1278. [CrossRef]

126. Kushner, J.I.V.; Deen, W.; Blankschtein, D.; Langer, R. First-principles, structure-based transdermal transport model to evaluate lipid partition and diffusion coefficients of hydrophobic permeants solely from stratum corneum permeation experiments. J. Pharm. Sci. 2007, 96, 3236-3251. [CrossRef]

127. Trucco, G.; Liberali, V. Analog Design Issues for Mixed-Signal CMOS Integrated Circuits. In Advances in Analog Circuits; Tlelo-Cuautle, E., Ed.; InTechOpen: London, UK, 2011.

128. Waldstein, S.M.; Gerendas, B.S.; Montuoro, A.; Simader, C.; Schmidt-Erfurth, U. Quantitative comparison of macular segmentation performance using identical retinal regions across multiple spectral-domain optical coherence tomography instruments. Br. J. Ophthalmol. 2015, 99, 794-800. [CrossRef]

129. Ronneberger, O.; Fischer, P.; Brox, T. U-net: Convolutional networks for biomedical image segmentation. Lect. Notes Comput. Sci. 2015, 9351, 234-241.

130. Loizos, K.; RamRakhyani, A.K.; Anderson, J.; Marc, R.; Lazzi, G. On the computation of a retina resistivity profile for applications in multi-scale modeling of electrical stimulation and absorption. Phys. Med. Biol. 2016, 61, 4491-4505. [CrossRef] [PubMed]

131. Cela, C.J.; Lee, R.C.; Lazzi, G. Modeling Cellular Lysis in Skeletal Muscle Due to Electric Shock. IEEE Trans. Biomed. Eng. 2011, 58, 1286-1293. [CrossRef] [PubMed]

132. Marc, R.E.; Jones, B.W.; Watt, C.B.; Anderson, J.R.; Sigulinsky, C.; Lauritzen, S. Retinal connectomics: Towards complete, accurate networks. Prog. Retin. Eye Res. 2013, 37, 141-162. [CrossRef] [PubMed]

(C) 2020 by the authors. Licensee MDPI, Basel, Switzerland. This article is an open access article distributed under the terms and conditions of the Creative Commons Attribution (CC BY) license (http://creativecommons.org/licenses/by/4.0/). 